\title{
Contributions from DMS and ship emissions to CCN observed over the summertime North Pacific
}

\author{
L. Langley ${ }^{1, *}$, W. R. Leaitch ${ }^{2}$, U. Lohmann ${ }^{3}$, N. C. Shantz ${ }^{4, * *}$, and D. R. Worsnop ${ }^{5}$ \\ ${ }^{1}$ Dalhousie University, Halifax, Nova Scotia, Canada \\ ${ }^{2}$ Environment Canada, Toronto, Ontario, Canada \\ ${ }^{3}$ Institute for Atmospheric and Climate Science, ETH Zurich, Switzerland \\ ${ }^{4}$ University of Toronto, Toronto, Ontario, Canada \\ ${ }^{5}$ Aerodyne Research Incorporated, Billerica, Massachusetts, USA \\ * now at: Meteorological Service of Canada, Dartmouth, Nova Scotia, Canada \\ ** now at: Environment Canada, Toronto, Ontario, Canada
}

Received: 18 September 2008 - Published in Atmos. Chem. Phys. Discuss.: 6 January 2009

Revised: 7 January 2010 - Accepted: 8 January 2010 - Published: 5 February 2010

\begin{abstract}
Measurements of cloud condensation nuclei (CCN) made over the North Pacific Ocean in July 2002 are analysed with concurrent measurements of aerosol number, mass and composition. Overall the $\mathrm{CCN}$ are controlled by the sulphate, including one case that suggests particle nucleation and growth resulting from dimethyl sulphide oxidation that enhanced CCN concentrations. Hourly CCN concentrations are correlated with concentrations of sulphate plus methanesulphonic acid (MSA) over the entire study period $\left(r^{2}=0.43\right.$ and 0.52 for supersaturations of $0.34 \%$ and $0.19 \%$, respectively), and are not well correlated with other organics $\left(r^{2}<0.2\right)$. One case study reveals elevated mass and number concentrations of ultrafine and fine organic particles due to regional ship emissions, identified through quadrupole aerosol mass spectrometer (Q-AMS) measurements, during which organic mass concentrations are correlated with CCN values $\left(r^{2}=0.39\right.$ and 0.46 for supersaturations of $0.19 \%$ and $0.34 \%$, respectively). The evolution of the time series and mass distributions of organics, sulphate and MSA over this timeframe indicate that the regional distribution of small, diffuse ship-sourced organic particles act as condensation sites for sulphur species, resulting in a subsequent increase in number concentrations of $\mathrm{CCN}$. We conclude that, where present, direct emissions of anthropogenic organic particles may exert a strong control on marine $\mathrm{CCN}$ concentrations once diffused into the marine atmosphere, by acting as condensation sites for biogenic and anthropogenic sulphur species.
\end{abstract}

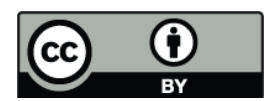

Correspondence to: L. Langley (lisa.langley@ec.gc.ca)

\section{Introduction}

The Canadian Surface Ocean - Lower Atmosphere Study (C-SOLAS) conducted the Subarctic Ecosystem Response to Iron Enrichment Study (SERIES) in the North Pacific Ocean in July 2002 (Boyd et al., 2003). Goals of the study included characterizing the chemical and physical composition of the marine aerosol and investigating the processes that determine aerosol cloud condensation nuclei $(\mathrm{CCN})$ concentrations in the open marine environment. Sulphate and organics are dominant components of the fine particle marine aerosol (Quinn and Bates, 2005), yet their respective sources and their roles in the formation of $\mathrm{CCN}$ are still unclear. In particular, the role of organics in aerosol processes and cloud activation is poorly understood compared with that of sulphate. Lohmann and Leck (2005) identify the importance of surface-active submicron organic aerosols in explaining observed CCN concentrations in pristine Arctic clouds. The inclusion of only small amounts of internally-mixed soluble inorganics is found to dramatically increase the ability of organic aerosols to act as $\mathrm{CCN}$, underscoring the importance of understanding the properties of an internally-mixed aerosol distribution (Lohmann et al., 2004). O'Dowd et al. (2004) suggest that organics, injected to the atmosphere through surface bubble activity, dominate the submicrometre aerosol number during marine bloom periods over the Atlantic Ocean, and the addition of the organic aerosol to sulphate+sea salt aerosol distributions can increase the cloud droplet number concentrations by $30-100 \%$. The presence of organics in cloud droplets has been demonstrated by Russell et al. (2000).

Published by Copernicus Publications on behalf of the European Geosciences Union. 
Pirjola et al. (2000) show evidence for dimethyl sulphide (DMS)-derived particle nucleation in modelled marine boundary layer conditions, but question the possibility of observing nucleation events in the field due to insufficient sources of condensable material. Very few reports exist of new particle formation in the open ocean boundary layer (e.g. Clarke et al., 1998; Covert et al., 1992; Hoppel et al., 1990; Weber et al., 1998); the elevated concentrations of DMS in the SERIES sample region make it a promising location for investigating new particle formation and in general to look for evidence related to a DMS-CCN climate feedback mechanism. This feedback cycle, proposed by Shaw (1983) and Charlson et al. (1987), hypothesizes that nucleation, growth, and water uptake of sulphate and MSA derived from the oxidation of DMS leads to the modification of the reflectivities (Twomey, 1974) and lifetimes (Albrecht, 1989) of marine clouds. Here, the investigation is extended to the interaction of ship-sourced organics and the products of DMS oxidation in determining $\mathrm{CCN}$ concentrations in the marine environment.

Ship-going vessels have recently been identified as a major, weakly regulated global anthropogenic emissions source (i.e. MARPOL $73 / 78^{1}$; Corbett and Fischbeck, 1997). Ship emissions account for approximately $15 \%$ of both $\mathrm{SO}_{2}$ and $\mathrm{NO}_{\mathrm{x}}$ emissions globally (Corbett and Fischbeck, 1997), and the change in global radiative forcing due to the contribution of ship-sourced sulphate to $\mathrm{CCN}$ concentrations has been estimated to be $-0.11 \mathrm{~W} \mathrm{~m}^{-2}$, or $14 \%$ of total estimated indirect forcing from anthropogenic sulphate (Capaldo et al., 1999). The contribution of organic carbon to particulate matter emitted from an ocean-going vessel was estimated by Agrawal et al. (2008) to be $15 \%$ of the total PM mass. In the present study direct fumigation of the instruments from one of the three platforms involved in the study resulted in sharp increases in concentrations of small particulates, $\mathrm{SO}_{2}$, and organic carbon, with little particulate sulphate (Phinney et al., 2006) as a result of the short time between emission and measurement of the plume, leaving little time for oxidation of $\mathrm{SO}_{2}$ to sulphate. However it points to the importance of organic carbon emissions from ocean-going ships, and moves us to investigate the impacts of these organics on the evolution of the aerosol and on CCN concentrations in the marine atmosphere. Russell et al. (1999) note that during the Monterey Area Ship Tracks (MAST) experiment, "condensation of $\mathrm{H}_{2} \mathrm{SO}_{4}$ from gas-phase oxidation of $\mathrm{SO}_{2}$ is primarily responsible for adding soluble sulphate mass to the newly emitted black and organic carbon particles." The authors emphasize the uncertainty in the relationship between organics and $\mathrm{CCN}$, and conclude that the nature of the insoluble and

\footnotetext{
${ }^{1}$ International Convention for the Prevention of Pollution from Ships, 1973, as modified by the Protocol of 1978 relating thereto: Annex VI - Regulations for the Prevention of Air Pollution from Ships, adopted 1997 and enforced as of 19 May 2005; www.imo. org.
}

slightly soluble carbon associated with ship emissions render it incapable of forming $\mathrm{CCN}$ under normal ambient supersaturations in the absence of sulphate.

Hobbs et al. (2000) conclude that primary diesel emissions are inefficient as $\mathrm{CCN}$; approximately $12 \%$ of particles emitted from diesel ships serve as CCN. However, the cloud nucleating properties of organics have been shown to improve with aging. Furutani et al. (2008) show a linear relationship between aerosol age and $\mathrm{CCN}$ activity: higher $\mathrm{CCN}$ activity and lower activation diameters were observed in more aged air masses.

In this paper, we examine the measurements of $\mathrm{CCN}$, particle number distributions and chemical mass concentrations (principally sulphate, MSA and total organic) collected over the North Pacific to further our understanding of the relationship between aerosol chemical constituents and $\mathrm{CCN}$ in the marine environment.

\section{Measurements}

Atmospheric aerosol measurements were conducted aboard the Mexican Research Vessel El Puma as part of the SERIES study near ocean station Papa $\left(50.0^{\circ} \mathrm{N}, 145.0^{\circ} \mathrm{W}\right)$ in the subarctic northeast Pacific (Fig. 1). Measurements were confined to a $1.5^{\circ} \times 1.5^{\circ}$ grid and a transect made from Station Papa back to port in Sidney, British Columbia. Atmospheric measurements included size-resolved particle number concentrations and chemical composition, number concentrations of cloud condensation nuclei $(\mathrm{CCN})$, trace gas mixing ratios, and meteorological variables. All times are reported as Pacific Daylight Savings Time (PDT; UTC-7). Local time in the sample area was approximately $1.5 \mathrm{~h}$ behind PDT, i.e. peak solar intensity in the sample area is observed at approximately 13:30 PDT. Size-resolved aerosol number concentrations for particles with mobility diameters $\left(D_{m}\right)$ between 8 and $290 \mathrm{~nm}$ were measured using a TSI Scanning Mobility Particle Sizer (SMPS; Model 3071 Electrostatic Classifier and a Model 3025 Ultrafine Condensation Particle Counter, UCPC). For spherical particles with no internal voids, the mobility diameter is equal to the physical diameter $\left(D_{p}\right)$. In this discussion, internal voids are assumed to be negligible, and the particles are considered to be spherical in the size range measured by the SMPS; thus the diameter measured by the SMPS is considered to be the physical diameter, $D_{p}$. Particle concentrations in each of 26 ranges of $D_{p}$ were logged every $5 \mathrm{~min}$. The accuracy of the particle concentration determined by the UCPC 3025 is $\pm 10 \%$ up to $10^{5} \mathrm{~cm}^{-3}$ (TSI, 2002).

An Aerodyne Quadrupole Aerosol Mass Spectrometer (QAMS) was used to obtain real-time quantitative measurements of the size and composition of non-refractory aerosol chemical species at 15-min resolution (Jayne et al., 2000). It does not allow for the measurement of refractory species, such as elemental carbon and sodium chloride, that evaporate 
slowly ( $t>$ a few seconds) at the temperature of the vaporizer. Non-refractory species that are internally-mixed with, or present on the surface of, refractory species (i.e. fine mode sea-salt-sulphate) are, however, detected by the QAMS (Jimenez et al., 2003). The instrument provides information on individual particle sizes and ensemble mass loadings, with limited information on individual particle composition. The transmission of particles into the Q-AMS is nearly $100 \%$ in the range of 0.06 to $0.6 \mu \mathrm{m}$ vacuum aerodynamic diameter $\left(D_{\mathrm{va}}\right)$, decreasing outside that range (Jayne et al., 2000; Zhang et al., 2002; Liu et al., 2007). The particle collection efficiencies and the relative ionization efficiencies are each incorporated into the analysis of the Q-AMS data. In this analysis the collection efficiency for all aerosol was set to 1 due to the high percentage of sulphuric acid in the aerosol, and the relative ionization efficiencies are as in Phinney et al. (2006). More detailed descriptions of the operation and calibration of the Q-AMS can be found elsewhere (e.g. Jayne et al., 2000; Allan et al., 2003).

In the Q-AMS, the $D_{\mathrm{va}}$ of the particle is determined from its time-of-flight in the vacuum chamber. The $D_{\mathrm{va}}$ is related to the volume equivalent diameter $\left(D_{\mathrm{ve}}\right)$ according to

$D_{\mathrm{va}}=\frac{\rho_{p} D_{v e}}{\rho_{0} X_{v}}$

where $\rho_{p}$ is the particle density (taking into account voids within the particle), $\rho_{0}$ is the reference density (unity), and $X_{v}$ is the dynamic shape factor, defined as the ratio of the drag force on the particle to the drag force on its volume equivalent sphere, when both move at the same velocity with respect to the gas (DeCarlo et al., 2004). Here, since the aerosol contains a significant fraction $(\sim 60 \%)$ of sulphuric acid and the sampling was done at relatively high relative humidity, the particles are assumed to be spherical with no internal voids of zero density. Thus, $D_{\mathrm{ve}}$ is equal to the physical diameter, $D_{p}$, and the relationship of $D_{\mathrm{va}}$ to $D_{\mathrm{ve}}$ is simplified to:

$D_{\mathrm{va}}=\rho_{p} D_{p}$

A pleated capsule filter placed over the Q-AMS inlet for $45 \mathrm{~min}$ (i.e. 3 sample averages) resulted in the following detection limits: sulphate: $0.02 \mu \mathrm{g} \mathrm{m}^{-3}$, MSA: $0.025 \mu \mathrm{g} \mathrm{m}^{-3}$, nitrate: $0.015 \mu \mathrm{g} \mathrm{m}^{-3}$, ammonium: $0.14 \mu \mathrm{g} \mathrm{m}^{-3}$, organics: $0.20 \mu \mathrm{g} \mathrm{m}^{-3}$. The mass concentrations of sulphate and MSA from the Q-AMS and those from size-segregated filter samples, collected with a static MOUDI, compared within $2 \%$ and 30\%, respectively (Phinney et al., 2006). MSA was diagnosed for the first time using a Q-AMS in Phinney et al. (2006) and these data are used in the present work. Appendix A details the experimental determination of the MSA fragmentation.

CCN observations were made using a University of Wyoming Model MA100 thermal gradient static cloud diffusion chamber (de Oliveira and Vali, 1995; Snider et al.,
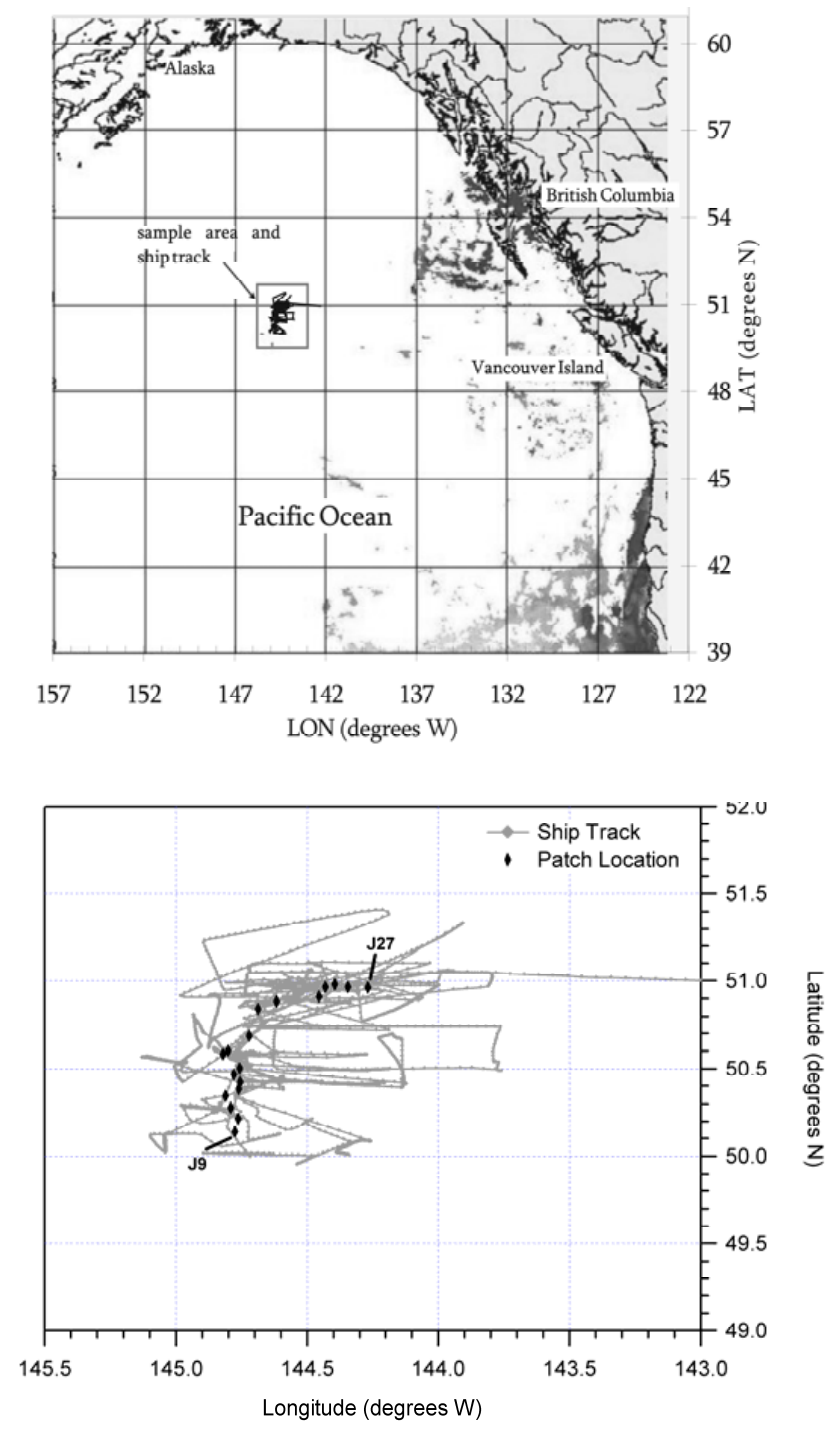

Fig. 1. (a) Map of sample area and ship track. Measurements were taken near Station Papa, in the Sub-Arctic North East Pacific Ocean, $142^{\circ}-155^{\circ} \mathrm{W}, 48^{\circ}-51^{\circ}$ N. (b) Expanded view of El Puma ship track, and patch location as it drifted towards the northeast, from 9 July to 27 July 2002 (from Phinney et al., 2006).

2006). Droplets grown in the chamber scatter light in proportion to their size, and the scattered intensity is converted to an analogue voltage. The CCN number concentration is approximately linearly dependent on deltaV (the difference between the signal from the scattered light and the baseline voltage) and can thus be calculated by multiplying deltaV by a constant. Laboratory calibration of the CCN counter for sulphate particles ranging in size from $75 \mathrm{~nm}$ to $240 \mathrm{~nm}$ found the following relationships between $\mathrm{CCN}$ number concentration and deltaV, independent of particle size:

$\mathrm{CCN}_{0.19 \%}=\operatorname{deltaV} \cdot 185$
$\mathrm{CCN}_{0.35 \%}=\operatorname{deltaV} \cdot 130$ 
for $\mathrm{CCN}$ activated at $0.19 \%$ and $0.35 \%$ supersaturations, respectively. These equations are used to calculate $\mathrm{CCN}$ number concentration from deltaV in this paper. In laboratory experiments, the addition of organics to sulphate particles has been shown to slow water uptake due to the lower solubility of organics compared with sulphate (Shantz et al., 2003). Thus, for the same number of CCN activated, the growth of $\mathrm{CCN}$ in the chamber would decrease with the presence of organics, thus decreasing the scatter and reducing the deltaV. The given conversion of deltaV to CCN number would then yield a lower CCN number in the "high organics" case, making our reports of $\mathrm{CCN}$ number conservative when organics comprise a significant fraction of the aerosol. The uncertainty in the CCN measurement is mainly based on the calibration factor, and is estimated to be $25 \%$ (Leaitch et al., 1999).

The $\mathrm{SO}_{2}$ data were collected at 1-min resolution using a TECO Model 43C-TL $\mathrm{SO}_{2}$ analyser. Zero air was periodically run through the instrument. The detection limit of $0.13 \mathrm{ppbv}\left(0.37 \mu \mathrm{g} \mathrm{m}^{-3}\right)$ was determined from two standard deviations of the mean of the zero data. The baseline was interpolated in time from the 130 zero points. Calibrations were made using a diluted $\mathrm{SO}_{2}$ NIST standard.

Measurements of $\mathrm{SO}_{2}$, aerosol and $\mathrm{CCN}$ affected by direct emissions from the sampling platform (El Puma) during stationary periods, as well as one or two instances when the winds were from the stern at a greater speed than the ship's speed, have been removed. The occasional periods when exhaust from one of the other two sampling platforms (C. S. S. Tully, Canada, and Kaiyo Maru, Japan) directly affected the sampling have also been removed.

The atmospheric DMS data presented here were collected approximately every hour approximately $10 \mathrm{~m}$ above the sea surface (Phinney et al., 2006). Samples were analysed using a Hewlett Packard 5890 Gas Chromatograph equipped with a Sievers sulphur chemiluminescence detector (SCD Model 355). The analytical detection limit was $0.1 \mathrm{pptv}$.

The meteorological variables temperature, relative humidity, barometric pressure, relative wind speed, and relative wind direction were logged at 10-minute intervals by the on-board meteorological instruments, located approximately $20 \mathrm{~m}$ above sea level. General meteorological conditions were overcast with several periods of fog, with clear sky periods exhibited on approximately six days. Winds were predominantly from the western quadrants at an average of $30 \mathrm{~km} \mathrm{~h}^{-1}$. Information on other instrumentation used in this study can be found in Marshall et al. (2005), Phinney et al. (2006), and Shantz et al. (2008).

Measurements made at Ocean Station Papa by the SERIES researchers in the days prior to the iron fertilization revealed high levels of DMS in the surface water (up to $15 \mathrm{nmol} \mathrm{L}^{-1}$ ) (Levasseur et al., 2006). After the fertilization, DMS concentrations in the unfertilized waters surrounding the patch peaked at $27 \mathrm{nmol} \mathrm{L}^{-1}$ on day 10 , a natural increase coinciding with a period of lower wind speeds and high irradiance resulting in a shallow wind mixed layer (Levasseur et al., 2006). While the levels of DMS inside the iron-enriched patch peaked at $36.9 \mathrm{nmol} \mathrm{L}^{-1}$ on day 10 , the sea-to-air flux of DMS was higher in the patch vs out of the patch only on days 4-7, and reached a peak both inside and outside the patch on days 10 and 11, corresponding to a period of high winds and surface layer ventilation (Wadleigh et al., 2002). The temporal pattern of DMS concentrations inside and outside the patch were not statistically different (Levasseur et al., 2006). The temporal pattern of atmospheric DMS roughly followed the flux, increasing significantly only on days 10 through 15, coincident with the highest DMS fluxes both in and out of the patch. No significant differences in atmospheric DMS concentrations were observed in or downwind of the patch vs out or upwind of the patch (Wadleigh et al., 2002; Norman and Wadleigh, 2007). In a calculation similar to that of Norman and Wadleigh (2007) who estimate the fertilized patch area to be approximately $0.02 \%$ of the fetch area sampled at Uclulet, BC, during SERIES, we estimate the linear patch dimension (which ranged from $8 \mathrm{~km}$ at the beginning of the experiment, to approximately $35 \mathrm{~km}$ by the end), to represent between $0.1 \%$ and $0.4 \%$ of the linear fetch sampled by the atmospheric measurements on El Puma, assuming an average wind speed of $25 \mathrm{~km} \mathrm{~h}^{-1}$, a total sample time of $672 \mathrm{~h}$, and with the assumption that we sampled in or downwind of the patch $50 \%$ of the time. All these results suggest that any differences in the concentrations of atmospheric DMS and its oxidation products due to the iron fertilization would be masked by the comparatively large fetch sampled by the measurements. The areal extent of the naturally enriched DMS concentrations encountered in the sample area is estimated in Sect. 3.2.2.

\section{Results and analysis}

\subsection{Ambient aerosol time series}

Time series' for data collected between 13-30 July 2002 are shown in Fig. 2; the mass concentrations of sulphate, total organics, and MSA measured by the Q-AMS in Fig. 2a, the number concentrations of particles in four ranges of physical diameter in Fig. 2b, and the observed concentrations of CCN activated at $0.19 \%$ and $0.34 \%$ supersaturations in Fig. 2c.

The mass concentration of sulphate varies from below detection limit (BDL) to $2.2 \mu \mathrm{g} \mathrm{m}^{-3}$, MSA varies between $\mathrm{BDL}$ and $1.0 \mu \mathrm{g} \mathrm{m}^{-3}$, and total organics range from BDL to $1.1 \mu \mathrm{g} \mathrm{m}^{-3}$. Average mass concentrations are $0.75 \mu \mathrm{g} \mathrm{m}^{-3}$, $0.18 \mu \mathrm{g} \mathrm{m}^{-3}$, and $0.30 \mu \mathrm{g} \mathrm{m}^{-3}$, respectively. The concentrations of MSA were an order of magnitude higher than concentrations observed over the North Pacific between Washington and Hawaii (Quinn et al., 1993), twice as high as those observed in the South Atlantic (Zorn et al., 2008) and also higher than that observed at Cape Grim, Tasmania (Andreae et al., 1999). The MSA concentrations reflect 

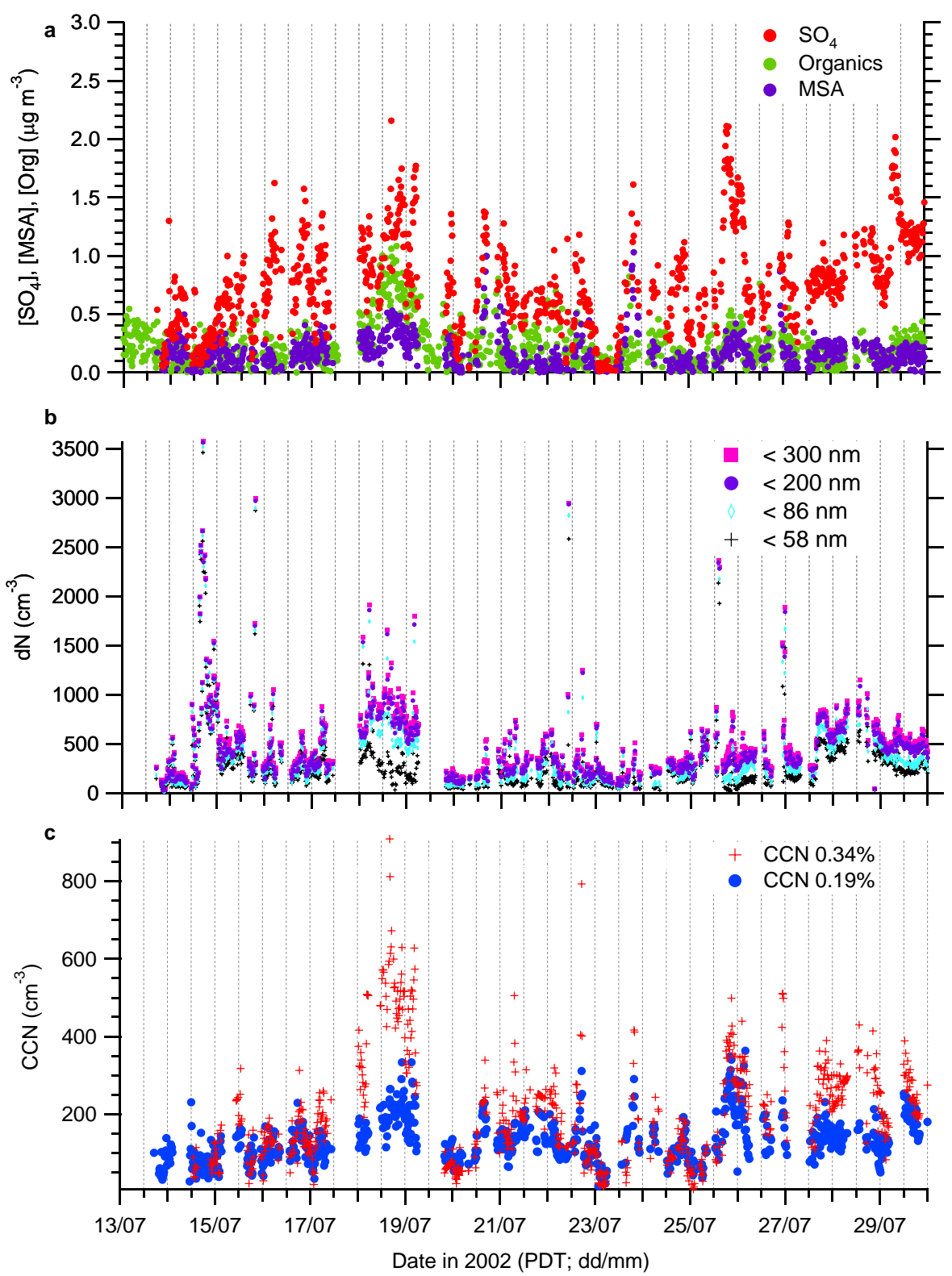

Fig. 2. Time series of data collected 13-30 July 2002, in the Northeast Pacific Ocean. The graphs show (a) mass concentrations of sulphate, MSA, and organics measured by the Q-AMS, (b) number concentration of particles in four size intervals measured by the SMPS, and (c) number concentrations of $\mathrm{CCN}$ active at $0.19 \%$ and $0.34 \%$ supersaturation.

the elevated DMS concentrations in the region, which were four times greater than recent measurements over the North Pacific Ocean (Arinami and Tsunogai, 2004). The average sulphate mass concentration measured in this study is higher than the biogenic sulphate contribution to $\mathrm{PM}_{2.5}$ of $0.3 \mu \mathrm{g} \mathrm{m}^{-3}$ measured on the Pacific Coast of Canada (Norman et al., 2006), and is also higher than the background marine concentration of $0.14 \mu \mathrm{g} \mathrm{m}^{-3}$ measured in the Southern Ocean (Sievering et al., 2004). The mean organic concentration is lower than the levels measured on the west coast of Ireland (O'Dowd et al., 2004). The period with the highest organic mass concentrations $\left(>1 \mu \mathrm{g} \mathrm{m}^{-3}\right)$ observed during the present study is examined in Sect. 4.

The number concentrations of particles with diameters less than $300 \mathrm{~nm}$ vary from 0 to $3500 \mathrm{~cm}^{-3}$ (Fig. 2b). The mean concentration of $500 \mathrm{~cm}^{-3}$ is at the upper end of typical marine boundary layer particle concentrations (e.g. Peng et al., 2002). A period of elevated concentrations of particles with diameters smaller than $58 \mathrm{~nm}$ is examined in Sect. 3.2.2.

The CCN number concentrations vary from 27 to $360 \mathrm{~cm}^{-3}$ for CCN active at $0.19 \%$ supersaturation $\left(\mathrm{CCN}_{0.19 \%}\right)$ and from 7 to $900 \mathrm{~cm}^{-3}$ for $\mathrm{CCN}$ active at $0.34 \%$ 
supersaturation $\left(\mathrm{CCN}_{0.34 \%}\right)$. The highest $\mathrm{CCN}$ concentrations were observed on 18 July, which coincides with the highest observed organic aerosol concentrations. Shantz et al. (2008) describe the CCN growth rates relative to the aerosol chemical and microphysical properties for the cases of 16,18 , and 27 July. In the present work, the factors controlling the $\mathrm{CCN}$, and the evolution of the aerosol in two case studies, are examined.

\subsection{Factors determining CCN}

The supersaturations at which the $\mathrm{CCN}$ were measured $(0.19 \%$ and $0.34 \%)$ are typical peak supersaturations for marine stratus and stratocumuli (e.g. Albrecht et al., 1989), the predominant cloud cover in this region during this study. Based on the Köhler equation and assuming the composition of sulphuric acid, the supersaturations of $0.19 \%$ and $0.34 \%$ should activate particles with diameters larger than $86 \mathrm{~nm}$ and $58 \mathrm{~nm}$ respectively. Sulphuric acid is used in the calculations because the majority of the aerosol mass $(\sim 60 \%)$ is acidic sulphate (Phinney et al., 2006). Figure 3 shows the relationship between the $\mathrm{CCN}$ concentration and the number concentration of aerosols with diameters larger than the critical radii. The plots contain points for the entire time series (13-30 July). The $r^{2}$ values of 0.62 and 0.83 for Fig. 3a and $\mathrm{b}$, respectively, indicate that most of the variance in the $\mathrm{CCN}$ is explained by the variance in the number concentrations of particles larger than the estimated theoretical activation diameter.

The effects of sulphate, new particle formation, biogenic sulphate and organics on the $\mathrm{CCN}$ are investigated in the following sections.

\subsubsection{Sulphate and $\mathrm{CCN}$}

In Fig. 4, concentrations of $\mathrm{CCN}_{0.19 \%}$ and $\mathrm{CCN}_{0.34 \%}$ are plotted against $\left[\mathrm{MSA}+\mathrm{SO}_{4}\right]$ for the whole time series. Approximately $50 \%$ of the variations in the $\mathrm{CCN}_{0.19 \%}\left(r^{2}=0.53\right)$ and in the $\mathrm{CCN}_{0.34 \%}\left(r^{2}=0.48\right)$ are explained by variations in $\left[\mathrm{MSA}+\mathrm{SO}_{4}\right]$. The slope of the $\left[\mathrm{MSA}+\mathrm{SO}_{4}\right]-\mathrm{CCN}_{0.34 \%}$ trend line is three times higher than that of $\left[\mathrm{MSA}+\mathrm{SO}_{4}\right]$ $\mathrm{CCN}_{0.19 \%}$ since the total particle number concentration is higher at the smaller diameter corresponding to $0.34 \%$ supersaturation and also because the higher supersaturation will increase the growth rate of the particles and hence the relative amount of light scattered by the CCN. The lower values of $r^{2}$ compared with the correlations with number (Fig. 3) are primarily a consequence of the difference between measuring particle mass vs number, i.e. most of the mass tends to be in large sizes.

\subsubsection{Case study of new particle formation from DMS}

On the afternoon of 14 July, number concentrations greater than $1000 \mathrm{~cm}^{-3}$ were observed for particles as small as
$8 \mathrm{~nm}$, and a subsequent increase in the number concentrations of particles with diameters of $30 \mathrm{~nm}-60 \mathrm{~nm}$ was observed through the morning of 15 July. Figure 5a shows the change in particle size distribution $(\mathrm{dN} / \mathrm{d} \log \mathrm{D})$ with time for 14 July. The data exhibits a shape characteristic of particle nucleation and growth with peak number concentrations at diameters $<10 \mathrm{~nm}$ preceding increases in larger particles over time (e.g. Kulmala et al., 2001; Buzorius et al., 2004). The concentrations of small particles begin to increase at about 14:00, and reach peak values at about 17:00. At $8.0 \mu \mathrm{m}^{2} \mathrm{~cm}^{-3}$, the sub-micron surface area in the three hours prior to the increase in particle concentrations is $70 \%$ lower than the average of $26 \mu \mathrm{m}^{2} \mathrm{~cm}^{-3}$ over the entire sample period (Fig. 5e), a factor favouring new particle formation in regions with lower levels of precursors (e.g. Clarke et al., 1998). A decrease in the relative humidity (RH) from $98 \%$ to $75 \%$ (Fig. 5a) occurs over the course of the increase in particle number concentrations between 12:00 and 15:00, likely the result of increasing temperature during the afternoon (Fig. 5b), and possibly due to mixing of dry air into the boundary layer. The reduced RH also will lower the ambient particle surface area.

The sulphate mass (Fig. 5b) is generally concentrated in particles with physical diameters between 150 and $400 \mathrm{~nm}\left(D_{\text {va }}\right.$ between 250 and $\left.700 \mathrm{~nm}\right)$, and is greater than $2.5 \mu \mathrm{g} \mathrm{m}^{-3}$ at times during this 42 -h interval. Consistent with the reduction in the particle surface area, the concentration of sulphate in this size range decreases to below $0.4 \mu \mathrm{g} \mathrm{m}^{-3}$ between 12:00 and 18:00 on 14 July, prior to the increase in small particles shown in Fig. 5a. Sunny conditions, favourable for particle nucleation, were observed on 14 July in contrast to the more frequent and vast coverage by stratus and stratocumulus, and the second highest value of insolation for the time series was observed on 14 July at 15:00 PDT (Fig. 5d).

Corresponding to the rise in insolation on 14 July, the DMS concentration in the air decreases from approximately $6 \mu \mathrm{g} \mathrm{m}^{-3}$ (2 ppbv) at $10: 30$ to about $2 \mu \mathrm{g} \mathrm{m}{ }^{-3}$ (0.7 ppbv) during the afternoon (Fig. 5c). An increase in the $\mathrm{SO}_{2}$ concentration from approximately $0.2 \mathrm{ppbv}$ to $0.35 \mathrm{ppbv}$ is observed from 12:00 to 15:00 (Fig. 5d), coincident with the rise in MSA (Fig. 5c) and particle numbers (Fig. 5a), and prior to the increase in sulphate concentration at approximately 18:00 (Fig. 5b). The increase in MSA and $\mathrm{SO}_{2}$ coincident with the decrease in DMS points to local-to-regional scale oxidation of DMS, while the rise in the sulphate concentration coincident with the growth of the particles (Figs. 5a and b) suggests condensation of oxidation products onto the nucleated aerosol particles. Berresheim et al. (2002) recorded decreases in MSA and $\mathrm{H}_{2} \mathrm{SO}_{4}$ correlated with rises in ultrafine particle concentrations in a coastal zone during low tide over a time period of $2-3 \mathrm{~h}$. The typical lifetime of DMS in the marine boundary layer with respect to $\mathrm{OH}$ oxidation is $0.5-$ 2 days (Wine et al., 1981; Hynes et al., 1986; Berresheim et al., 1990; the latter with a DMS concentration 2 orders of 

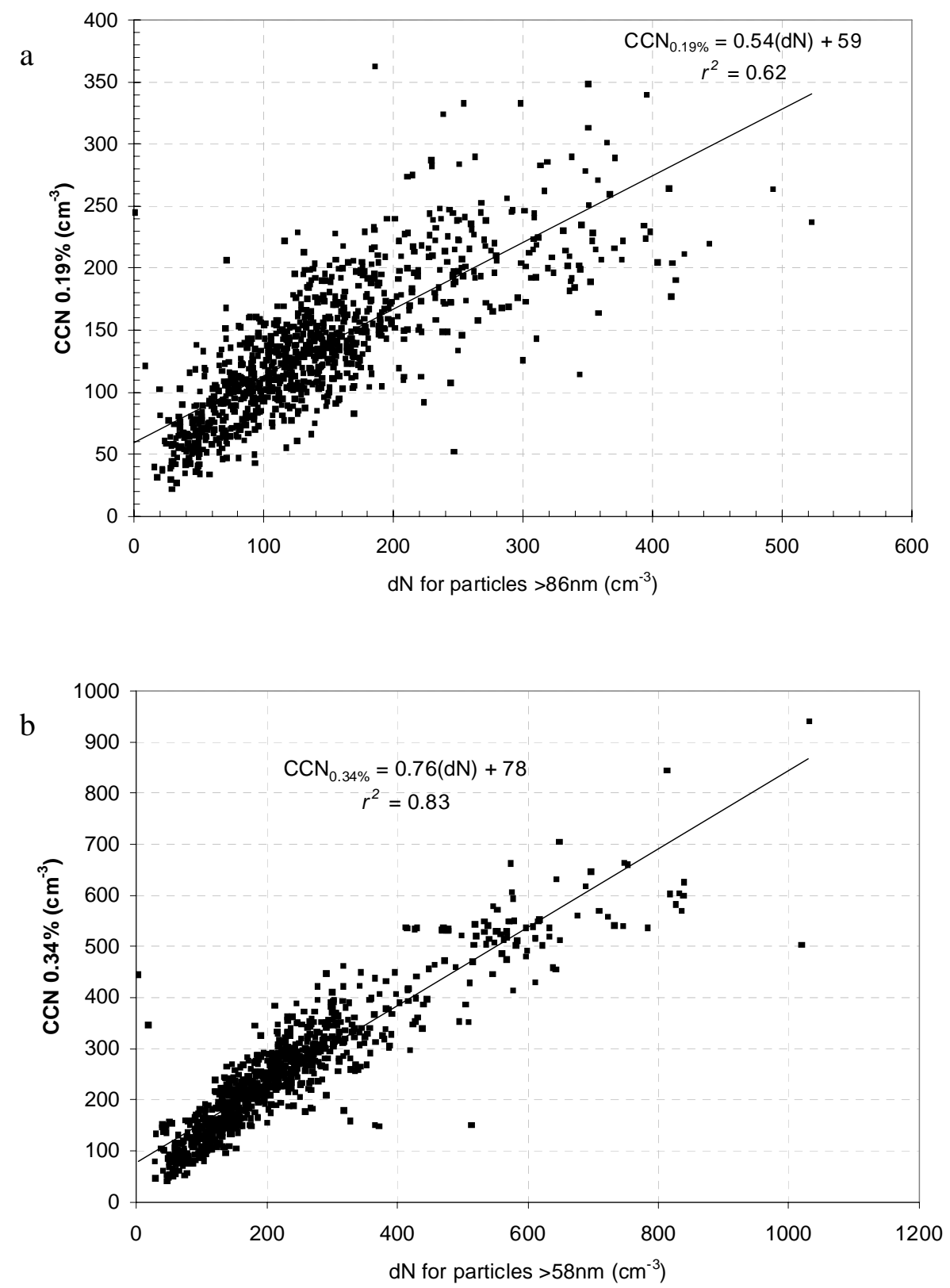

Fig. 3. Correlation of CCN number concentrations measured in the NE Pacific, 13-30 July 2002, with number concentrations of particles having diameters greater than the theoretical critical diameters of (a) $86 \mathrm{~nm}$ and (b) $58 \mathrm{~nm}$ for CCN active at $0.19 \%\left(\mathrm{CCN}_{0.19 \%}\right)$ and $0.34 \%$ $\left(\mathrm{CCN}_{0.34 \%}\right)$, respectively. Linear trendlines and correlation coefficients $\left(r^{2}\right)$ are shown.

magnitude smaller than that measured in the present study), and of $\mathrm{SO}_{2}$ is about one day (Berresheim et al., 1990), so it is reasonable to expect some quantity of DMS-to- $\mathrm{SO}_{4}$ conversion within $6-10 \mathrm{~h}$ under the sunny conditions encountered on 14 July, particularly with the high concentrations of atmospheric DMS that were measured.

The modelling work of Pirjola et al. (2000) indicates that in polar marine air masses binary $\mathrm{H}_{2} \mathrm{SO}_{4}$ nucleation can lead to particle concentrations on the order of $1000 \mathrm{~cm}^{-3}$, and ternary nucleation $\left(\mathrm{H}_{2} \mathrm{O}-\mathrm{H}_{2} \mathrm{SO}_{4}-\mathrm{NH}_{3}\right)$ can occur for marine boundary layer concentrations of sulphuric acid and ammonia concentrations on the order of $0.002 \mu \mathrm{g} \mathrm{m}^{-3}$ and $5 \mathrm{pptv}$, respectively. The authors suggest that ternary nucleation will result in enhancements in nanoparticles only for DMS concentrations greater than approximately of $0.4 \mathrm{ppbv}$. In our sample region DMS concentrations reached nearly $8 \mathrm{ppbv}$, with a mean concentration of about 2 ppbv. While ammonia was not measured during this study, Quinn et al. (1992) report concentrations of gas-phase ammonia of approximately 20 pptv over the north east Pacific Ocean, sufficient to initiate 


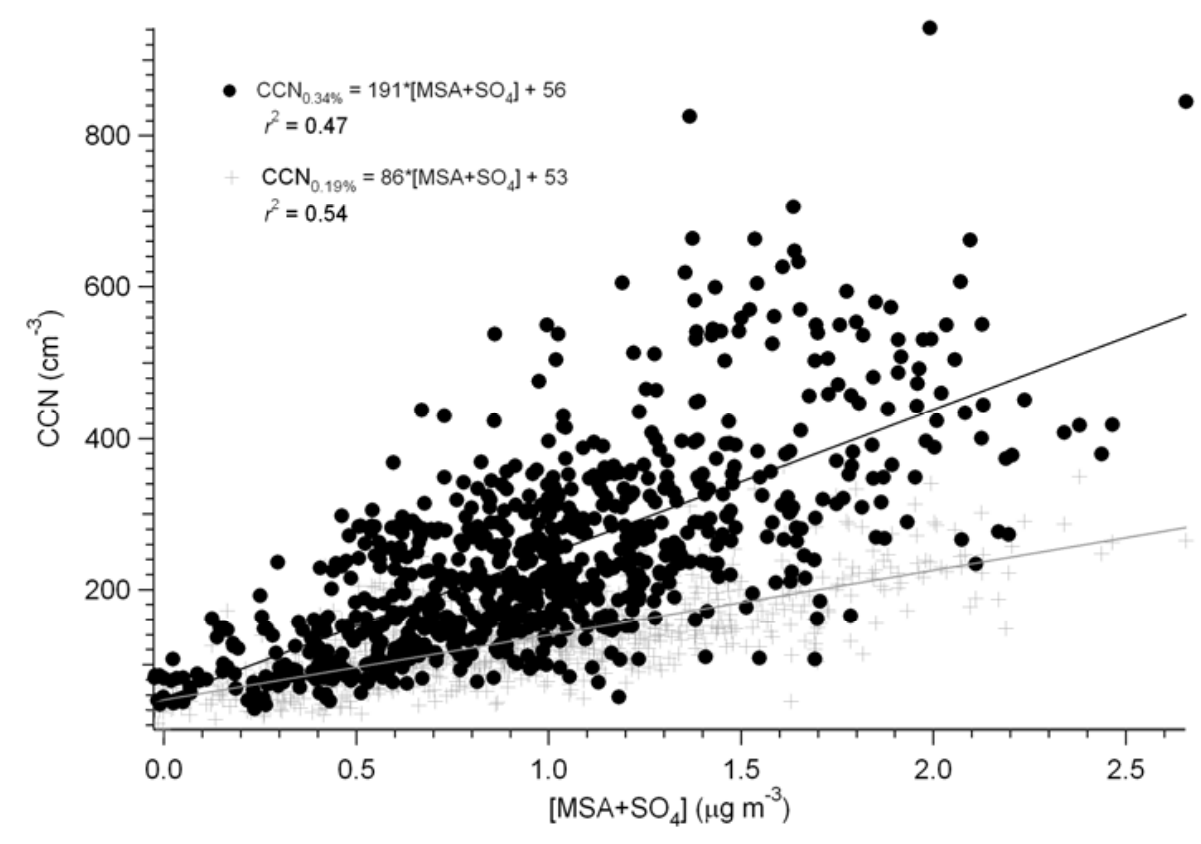

Fig. 4. Correlations of $\mathrm{CCN}_{0.19 \%}$ and $\mathrm{CCN}_{0.34 \%}$ each with $\left[\mathrm{MSA}+\mathrm{SO}_{4}\right]$ for 13-30 July 2002. Linear trendlines and correlation coefficients $\left(r^{2}\right)$ are shown.

ternary nucleation based on the model calculations of Pirjola et al. (2000). Thus, the sampled conditions were favourable and the results consistent with the possibility of ternary or binary particle nucleation.

Though it is hypothesized that boundary layer particle nucleation is the source of the small particles observed on 14 July, other explanations must be considered. A frontal passage yielding a new particle-rich air mass or subsidence and entrainment of newly formed particles into the boundary layer from the free troposphere aloft may be a plausible explanation for the burst of small particles. Surface analysis maps show little change in atmospheric conditions in the sample region, with a quasi-static low pressure system sitting to the northeast of the sample area from 13 July 23:00 to 15 July and beyond (Atlantic Climate Centre ${ }^{2}$ ). Drizzle and some rain was observed on 13 July, the precipitation clearing by 00:00 14 July. On 14 July the weather was overcast with some breaks in the cloud, with periods of sun reported at 12:00 and 17:00, and a brief period of fog/drizzle reported at 12:30 followed by breaks in the cloud cover. Between 14 July 03:00 and 15 July 03:00, surface winds are consistently from the northwest and atmospheric pressure varied between 1010 and $1011 \mathrm{mb}$. Though there was a change in cloud cover indicated by the insolation curve in Fig. 5, there is no evidence from surface meteorological analysis of any frontal passage. It is likely that the drizzle that occurred on 13 July, and briefly on 14 July, scavenged the surface area,

\footnotetext{
${ }^{2}$ Atlantic Climate Centre, climate.atlantic@ec.gc.ca; www.atl. ec.gc.ca/climate
}

and when followed by a brief period of sun provided the right conditions for nucleation.

During the 14 July event, the wind speed was 25$30 \mathrm{~km} \mathrm{~h}^{-1}$ and increases in small particle concentrations are seen approximately $6 \mathrm{~h}$ after DMS concentrations begin to decrease with the increase in solar irradiation at 09:00. The average winds were from the west, and for a 6-h lag time for nucleation, the source region would have extended at least $200 \mathrm{~km}$ to the west, well beyond the linear extent of the fertilized patch of ocean on day $6(8-20 \mathrm{~km}$; Law et al., 2006).

Figure 5e indicates that on 14 July between 12:00 and 18:00 the number concentration of smaller $\mathrm{CCN}\left(\mathrm{CCN}_{0.34 \%}\right)$ increases, corresponding to the increases in particle concentrations. The number concentration of larger $\mathrm{CCN}$ $\left(\mathrm{CCN}_{0.19 \%}\right)$ does not change significantly during this time, consistent with the sulphate distribution which does not start to show significant mass until after 18:00. Between 14 July 18:00 and 15 July 01:00, the concentrations of the smaller $\mathrm{CCN}$ decrease as the mass concentrations of sulphate and MSA, as well as the particle surface area, all increase. A closer look at the sulphate mass distribution reveals that the mode diameter decreased as the distribution broadened throughout the overnight period (Fig. 5b). This occurs because as mass condenses onto the entire distribution, the more numerous particles at the lower end of the distribution grow into the Q-AMS detection range $(>50 \mathrm{~nm})$.

The evidence presented above suggests particle nucleation from biogenic sulphate precursors was observed during our study. Concentrations of CCN increased during this event, then decreased as the particle distribution broadened. The 
a) Number (RH)

b) Sulphate

(T)
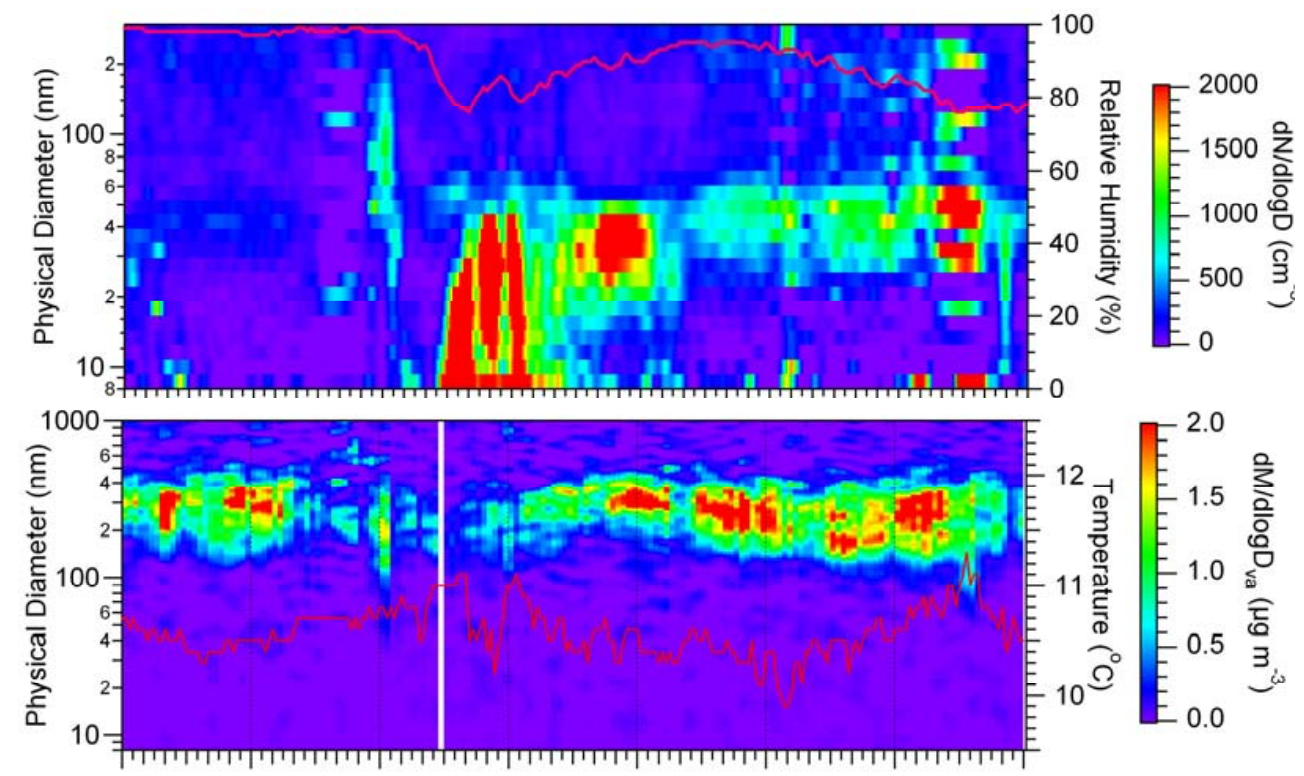

c) MSA

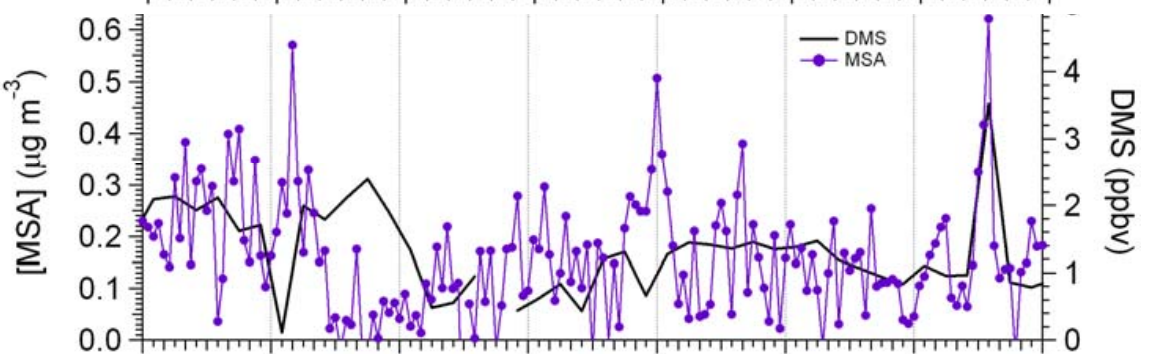

d) $\mathrm{SO}_{2}$

(insolation)

e) $\mathrm{CCN}$

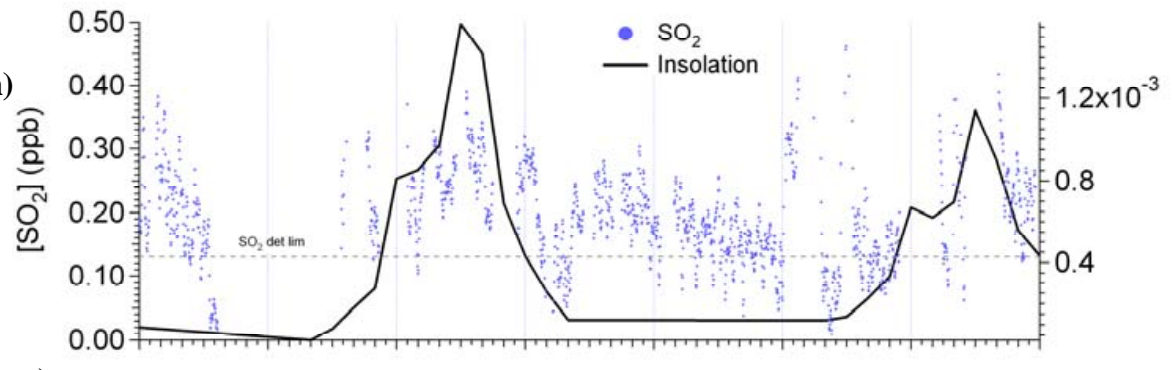

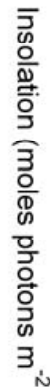

(surface area)

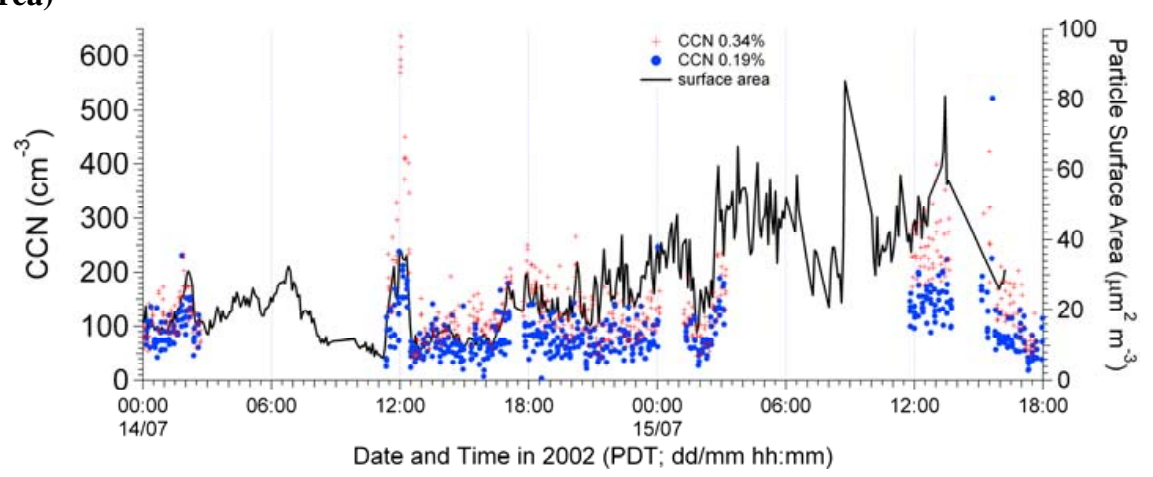

Fig. 5. Image plots of (a) $d N / d \log D$ and (b) sulphate $d M / d \log D$ (colour bars) vs time (x-axis) and physical diameter (left y-axis); relative humidity is overlaid as a line on plot (a), and temperature on (b), corresponding to the right y-axes. Time series of (c) MSA (left y-axis) and DMS (right y-axis) concentrations, (d) $\mathrm{SO}_{2}$ concentration (left y-axis) and insolation (right y-axis), (e) $\mathrm{CCN}$ active at two supersaturations (left y-axis) and surface area (right y-axis). All plots are for the time period 14 July, 00:00-15 July, 18:00. Note that the left y-axis is scaled differently in (a) than in (b). AMS aerodynamic diameters were converted to physical diameters using a density of $1.8 \mathrm{~g} \mathrm{~cm}^{-3}$. 

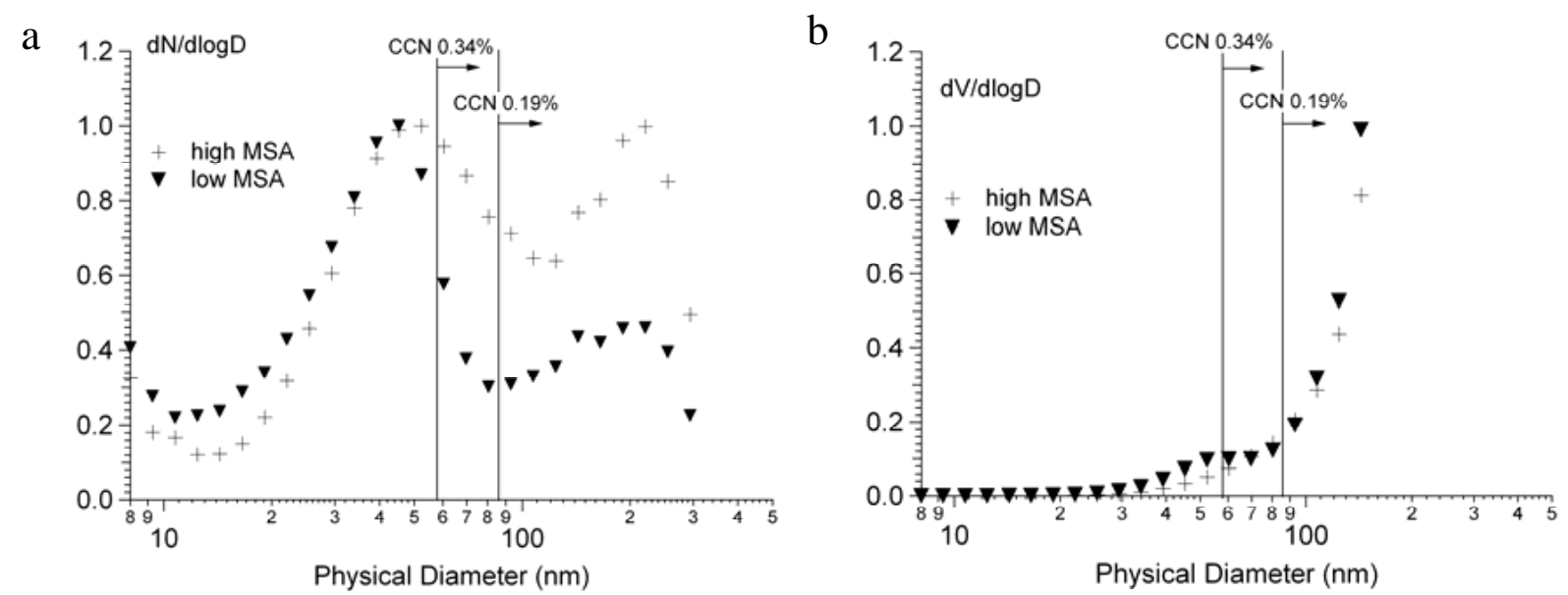

Fig. 6. (a) Size distribution of particle number concentration for times when peak MSA concentrations are greater than $0.5 \mu \mathrm{g} \mathrm{m}^{-3}(\mathrm{high}$ MSA), and less than $0.5 \mu \mathrm{g} \mathrm{m}^{-3}$ (low MSA), normalized by dividing the dN values by the peak dN value of their respective distribution. (b) Particle volume distribution derived from the number concentration for the conditions described in (a). Vertical bars indicate the activation diameter at each supersaturation. The number distributions show more particles with diameters larger than the CCN activation diameter for the high-MSA case, whereas the volume distribution shows little change.

Table 1. Properties of the aerosol distribution for points when [MSA] $<0.5 \mu \mathrm{g} \mathrm{m}^{-3}$ (low MSA; $N=717$ ) and when $\left[\mathrm{MSA}>0.5 \mu \mathrm{g} \mathrm{m}^{-3}\right.$ (high MSA; N=174). Percent difference is given for times of "high MSA" relative to "low MSA". $D_{\text {eff }}$ refers to the effective physical diameter of the particle distribution. The fraction of particles activated as CCN (CCN/CN) is $\sim 70 \%$ higher in the "high MSA" case than the "low MSA" case, at both supersaturations. The uncertainty of the CCN/CN ratio is $\pm\left(100 * \sqrt{0.1^{2}+0.25^{2}}\right) \%= \pm 27 \%$, thus the ratio of 1.06 , while physically implausible, falls within the experimental and calculated uncertainty range.

\begin{tabular}{lrrrrrrrrrr}
\hline & $\mathrm{SO}_{4}-\mathrm{CCN}_{0.19 \%}$ & \multicolumn{3}{c}{ - Particle number concentration $\left(\mathrm{cm}^{-3}\right)-$} & \multicolumn{2}{c}{$\mathrm{CCN}\left(\mathrm{cm}^{-3}\right)-$} & \multicolumn{2}{c}{$-\mathrm{CCN} / \mathrm{CN}-$} & \multicolumn{2}{c}{$D_{\text {eff }}(\mu \mathrm{m})$} \\
& slope & total & $D<58 \mathrm{~nm}$ & $D>58 \mathrm{~nm}$ & $D>86 \mathrm{~nm}$ & $0.34 \%$ & $0.19 \%$ & $0.34 \%$ & $0.19 \%$ & \\
\hline low MSA & 0.44 & 450 & 275 & 175 & 128 & 81 & 278 & 0.18 & 0.62 \\
high MSA & 0.64 & 350 & 141 & 209 & 152 & 104 & 370 & 0.3 & 1.06 & 0.22 \\
$\%$ diff & $45 \%$ & $-22 \%$ & $-49 \%$ & $19 \%$ & $19 \%$ & $28 \%$ & $33 \%$ & $67 \%$ & $71 \%$ & 0.22 \\
\hline
\end{tabular}

following section examines the role of biogenic sulphate on CCN concentrations.

\subsubsection{Biogenic sulphate and $\mathrm{CCN}$}

Higher mass concentrations of MSA are a marker for DMS oxidation and biogenic sulphate. To investigate the relationship of biogenic sulphate and CCN in this study, properties of the aerosol during times associated with peak MSA concentrations greater than $0.5 \mu \mathrm{g} \mathrm{m}^{-3}$ (the 98-th percentile value) are compared with those during times when MSA concentrations are lower than $0.5 \mu \mathrm{g} \mathrm{m}^{-3}$. Number concentrations of $\mathrm{CCN}_{0.19 \%}$ and $\mathrm{CCN}_{0.34 \%}$ increase by $30 \%$ during times associated with higher MSA concentrations (i.e. 20 July and 27 July) over those with lower MSA concentrations (Table 1). At both supersaturations, the fraction of particles activated as cloud condensation nuclei $(\mathrm{CCN} / \mathrm{CN})$ is approximately $70 \%$ higher during times when MSA concentration is high versus when MSA concentration is lower, and the slope of the sulphate- $\mathrm{CCN}_{0.19 \%}$ relationship increases by $45 \%$ (the slope of the sulphate- $\mathrm{CCN}_{0.34 \%}$ relationship showed no change). Possible explanations for the increase in $\mathrm{CCN}$ and slope may include a smaller $\mathrm{CCN}$ effective diameter (i.e. the size distribution of $\mathrm{CCN}$ is shifted to smaller, more numerous particles) or greater aerosol activation (i.e. particles have the same size distribution, but more of them activate) when MSA is present. Figure $6 \mathrm{a}$ and $\mathrm{b}$ show the number and volume distributions, respectively, of particles measured during times of high and low MSA concentration, normalized by dividing the $\mathrm{dN}$ values by the peak $\mathrm{dN}$ value of their respective distribution. The number distribution indicates a relative increase in numbers of particles $>58 \mathrm{~nm}$ (the theoretical activation diameter for sulphate particles at $0.34 \%$ supersaturation) and $>86 \mathrm{~nm}$ (theoretical activation diameter for sulphate particles at $0.19 \%$ supersaturation) when MSA concentrations are high, and shows that the distribution of particles 
large enough to act as $\mathrm{CCN}$ is not shifted towards smaller sizes. This suggests that the source of the higher $\mathrm{CCN} / \mathrm{CN}$ ratio is greater aerosol activation, rather than a shifted size distribution. Figure $6 \mathrm{~b}$ indicates that, though the $\mathrm{CCN}$ numbers increase, changes in the volume (proportional to mass) distribution are not apparent for particles in the activation range. This comparison of number and volume distributions at lower and higher MSA concentrations suggests that the impact of DMS oxidation on $\mathrm{CCN}$ in this instance is to increase the number concentrations of $\mathrm{CCN}$ active at supersaturations representative of marine stratiform clouds.

\subsubsection{The role of organics}

Figure 7a shows the correlation between the mass concentration of $\left[\mathrm{MSA}+\mathrm{SO}_{4}\right]$ and particles in the $200-300 \mathrm{~nm}$ physical diameter size range for 13-30 July. Of the particle size ranges shown in Fig. 2b, this size range is best correlated with $\left[\mathrm{MSA}+\mathrm{SO}_{4}\right]$; much of the variation in particles of this size can be explained by variations in $\left[\mathrm{MSA}+\mathrm{SO}_{4}\right]$. In the case of the 80-90 $\mathrm{nm}$ particles versus [MSA+SO 4 (Fig. 7b), two distinct trends are apparent. The upper trend is identified by episodes of higher number concentrations of $80-90 \mathrm{~nm}$ particles (in some cases up to $450 \mathrm{~cm}^{-3}$ ), and the leading and trailing tails of these episodes. The majority of these points occur during a 20 -h period on 18 July, a day with higher aerosol mass and number concentrations, including the highest measured organic mass concentrations (Fig. 2). In Fig. 7c, the $80-90 \mathrm{~nm}$ particle concentrations are plotted versus the organic mass concentrations for this 20 -h period. The coefficient of variation for the fit of the $80-90 \mathrm{~nm}$ particles with organic mass (Fig. 7c) is lower than with [MSA+SO 4 (upper curve of Fig. 7b), but the slope is over twice as high. The greater slope means that for a given increase in organic mass there is a greater increase in particle number than for the same increase in $\left[\mathrm{MSA}+\mathrm{SO}_{4}\right]$ mass. Equally, as the particle number goes up, the ratio of organic to sulphate mass goes down, indicating that throughout this size range the particles are not homogeneously mixed. This indicates that the number concentration of $80-90 \mathrm{~nm}$ particles is more sensitive to increases in organic mass than to increases in $\mathrm{SO}_{4}+\mathrm{MSA}$ mass. While more particles for a given mass can often be attributed to smaller particle sizes, this is not an explanation here because these plots show points for the same narrow size range of particles $(80-90 \mathrm{~nm})$. It is hypothesized that the increase in organic mass is directly related to increases in particles, whereas most of the sulphur mass condenses onto pre-existing particles, which increases the mass concentrations but leaves the numbers of particles unchanged. This hypothesis is investigated here.

Surface back trajectories were generally from the west during the study (13-30 July), but the surface and upper air analyses for 18 July show a quasi-stationary low, during which time the winds were light and the skies were clear (Fig. 8). Back trajectories show no contact with the continent as far back as five days (Fig. 8a). The concentrations of organics in the aerosol reach nearly $1 \mu \mathrm{g} \mathrm{m}^{-3}$, the highest concentrations observed during the study, and were sustained above $0.5 \mu \mathrm{g} \mathrm{m}^{-3}$ for nearly $24 \mathrm{~h}$ (Fig. 2a).

The mass spectrum of organic fragments from the Q-AMS averaged for the entire sample period (13-30 July), excluding 18 July and direct fumigation by ship exhaust, is shown in Fig. 9a, plotted as intensities relative to the highest peak. The highest contribution is from $m / z 44$, a signature of oxygenated organic compounds such as di- and poly-carboxylic acids, whose fragments contain $\mathrm{CO}_{2}^{+}$which dissociates from the organic molecule when hitting the vaporizer (Allan et al., 2004). The mass spectrum has contributions from the series $(m / z 27,41,55,69, \ldots)$, indicative of unsaturated hydrocarbons, whose masses are relatively more abundant than the series $(\mathrm{m} / \mathrm{z} 29,43,57,71, \ldots)$ which is representative of saturated hydrocarbons (Canagaratna et al., 2004). The mass fragment at $\mathrm{m} / \mathrm{z} 43$ can have contributions both from saturated hydrocarbons and oxidized organic species such as aldehydes or ketones. The peaks at $\mathrm{m} / \mathrm{z} 77$ and 91 are indicative of aromatic hydrocarbons (Canagaratna et al., 2004). By comparison the relative mass spectrum during a period of fumigation from the exhaust of our platform, El Puma, indicates a composition almost exclusively of hydrocarbons (alkanes, $m / z$ 29, 45, 57, 71, 85, .., $m / z$ 27, 41, 55, 69, 83, ... and $m / z, 67,81,95, \ldots$ ) (Fig. 9b).

The average spectrum for 18 July (Fig. 9c) shows a relative reduction in the intensity of $\mathrm{m} / \mathrm{z}, 44$ and relative enhancements in $m / z 43$ and 57 compared with Fig. 9a. The increased relative abundance of the hydrocarbon mass fragments (e.g. $m / z$ 67, 69, 71, 81, 83, 85, 95, 97, 109, 111) indicates evidence of a significant influence from a combustion source. The ratio of $\mathrm{m} / \mathrm{z} 44$ to the total organics concentration is both lower and more stable on 18 July than for other times (Fig. 9d), indicating a relatively non-oxygenated aerosol across this period compared with the study average. However, the oxygenated carbon content was not as low as that of direct ship exhaust, thus it gives the appearance of either slightly aged diesel emissions or diesel emissions mixed with a more oxygenated organic aerosol of other origin. Based on the atmospheric circulation and the mass spectra, it is conjectured that emissions from ships in the region slowly circulated, diffused, and eventually impacted our measurements.

Figure 10 shows an expanded view of Fig. 2, covering only 18 July. Vertical bars divide the event into six time periods (Period I, 00:00-03:45; Period II, 03:45-06:00; Period III, 06:00-07:30; Period IV, 09:00-12:30; Period V, 12:30-17:30; and Period VI, 18:00-23:30). These six intervals are chosen based on changes in the $\mathrm{CCN}$ and the relative concentrations of organic and sulphate masses. Period I is characterized by lower particle number concentrations and $\mathrm{CCN}$ scattering, and the average organic and sulphate mass concentrations are $0.33 \mu \mathrm{g} \mathrm{m}^{-3}$ and $1.00 \mu \mathrm{g} \mathrm{m}^{-3}$ respectively. In Period II, the number concentrations of particles 
a)

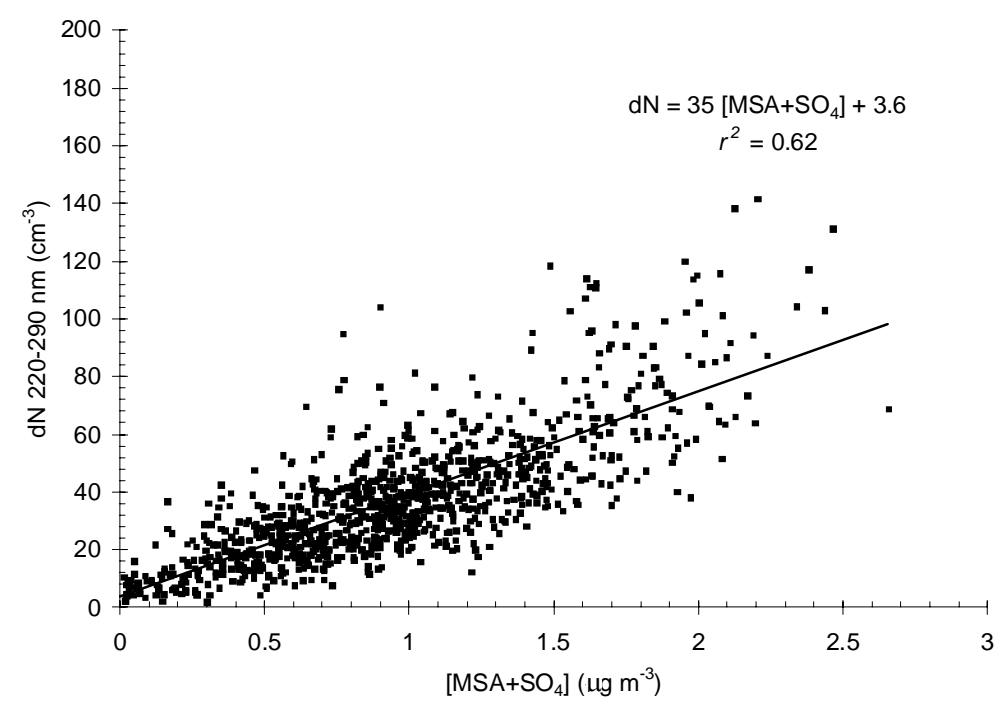

b)

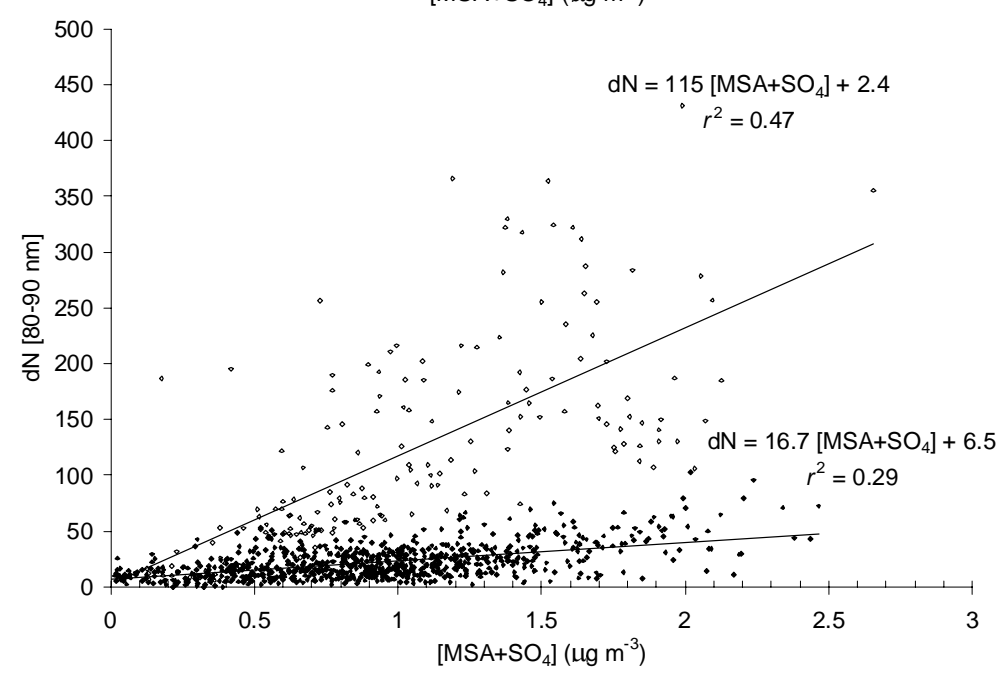

c)

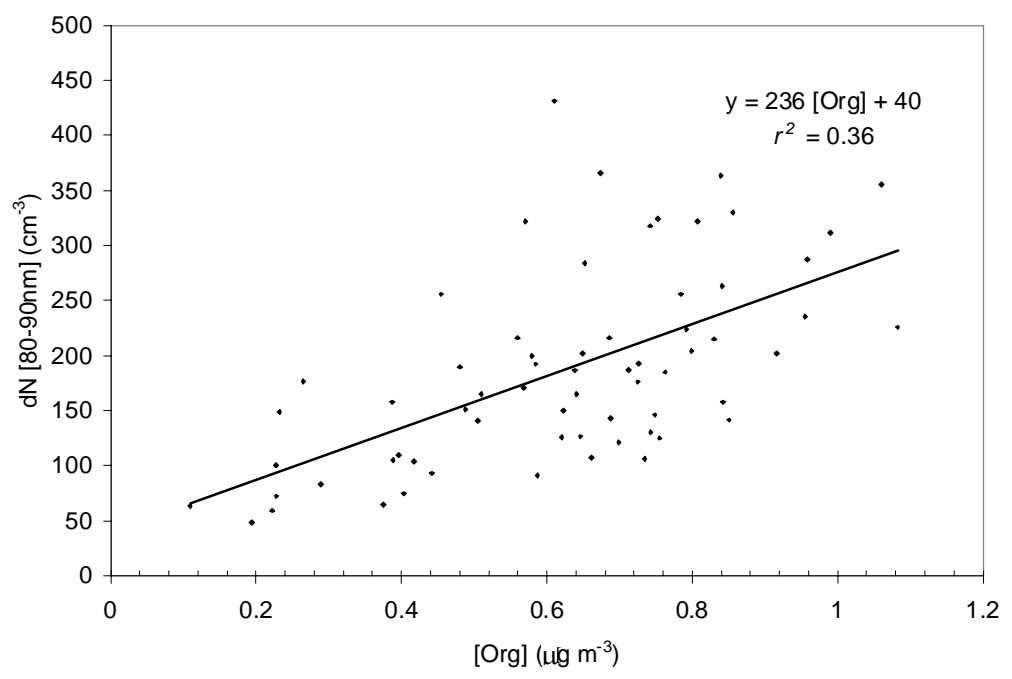

Fig. 7. (a) Correlation of $\left[\mathrm{MSA}+\mathrm{SO}_{4}\right]$ with the concentration of particles with physical diameters between 220 and $290 \mathrm{~nm}$, for 1330 July 2002; (b) correlation of [MSA+SO 4$]$ with concentrations of particles with physical diameters between 80 and $90 \mathrm{~nm}$. The data are divided into two trends, the upper trend identified by high particle number concentration; (c) correlation of organics with the concentration of particles with physical diameters between 80 and $90 \mathrm{~nm}$, for the points located in the upper trend in Fig. 6a. The best-fit linear trendlines and correlation coefficients are shown. 
a

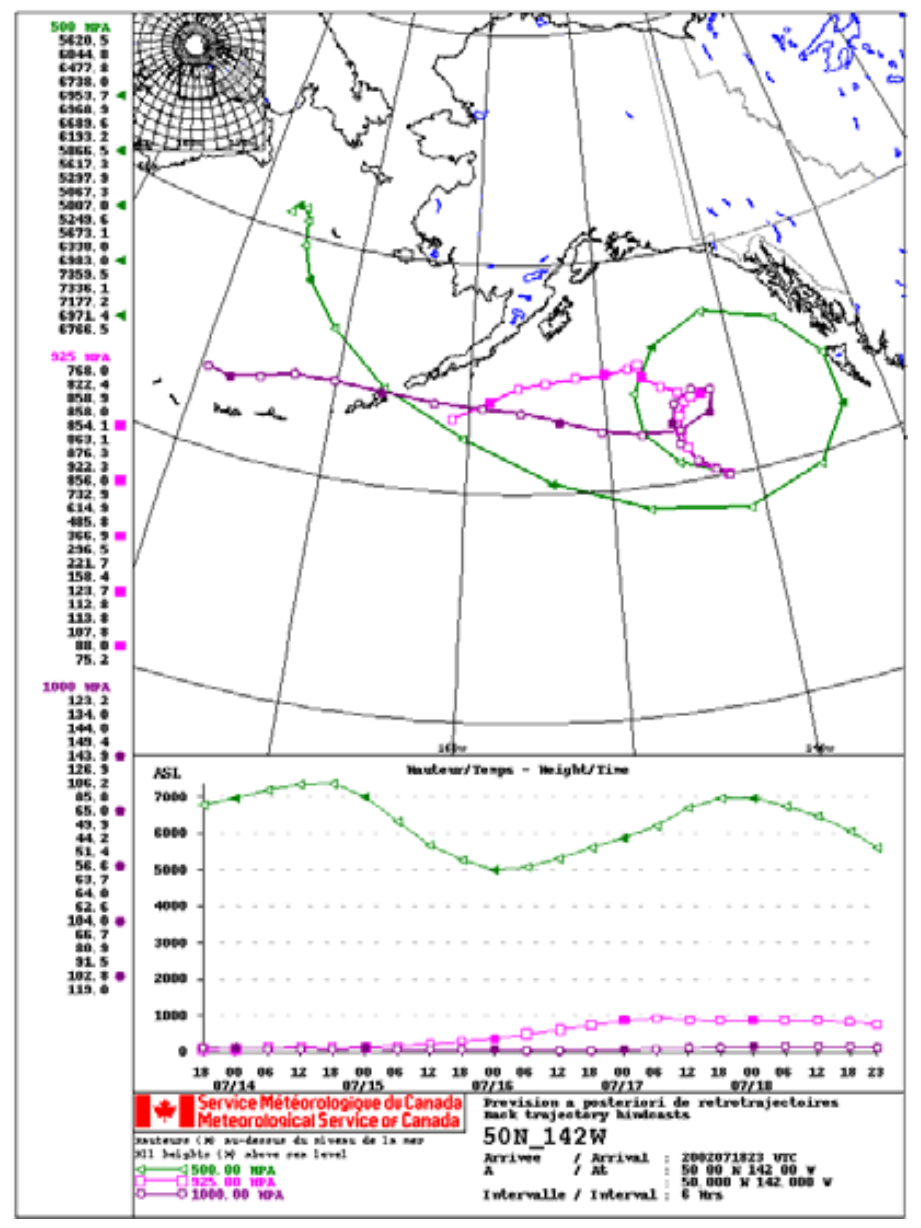

b Surface anal $2002071818 Z$

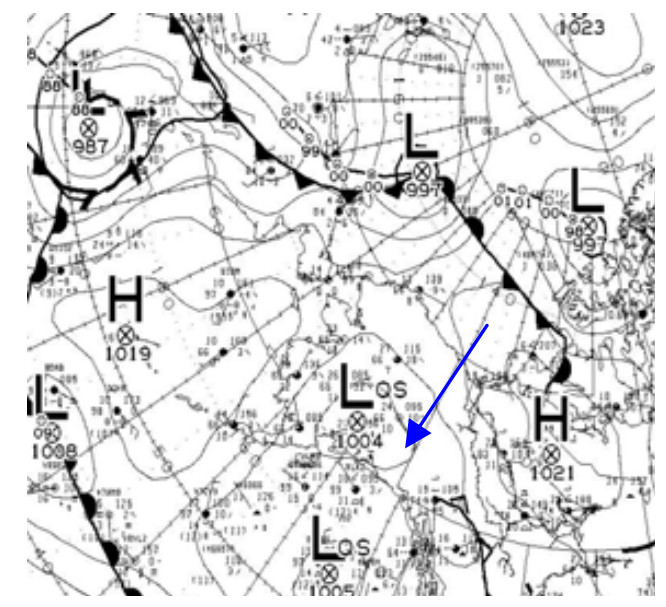

C 500 mb thickness $2002071812 \mathrm{Z}$

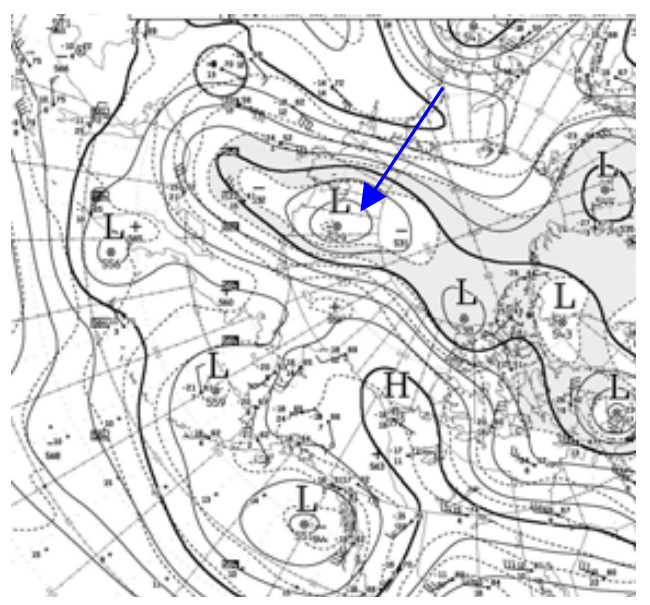

Fig. 8. (a) Five-day Canadian Meteorological Centre back trajectory for the sample location, $50^{\circ} \mathrm{N} 142^{\circ} \mathrm{W}$, near Station Papa, ending $18 \mathrm{July}, 23: 00$. The purple curve indicates the $1000 \mathrm{mb}$ (surface) trajectory; the pink curve represents the $925 \mathrm{mb}$ (long-range-transport) trajectory, and the green curve indicates the $500 \mathrm{mb}$ trajectory (steering flow). The lower graph shows the altitude (in $\mathrm{m}$ above sea level) of the air parcels along their respective trajectories. Surface (b) and upper air (c) analyses verify a stagnant system circling in the sample region on 18 July. The location of the quasi-stationary low is marked with a blue arrow (source: Atlantic Climate Centre ${ }^{2}$ ).

with diameters less than $86 \mathrm{~nm}$ increase from 700 to nearly $2000 \mathrm{~cm}^{-3}$, and the $\mathrm{CCN}$ active at $0.34 \%$ supersaturation increase. The mean organic and sulphate mass concentrations are $0.30 \mu \mathrm{g} \mathrm{m}^{-3}$ and $0.92 \mu \mathrm{g} \mathrm{m}^{-3}$ respectively, very close to those of Period I. The modal diameter for sulphate, MSA, and organics is $486 \mathrm{~nm}$ in both Period I and Period II, however there is a broadening in both sulphate and the organic mass distributions towards smaller sizes from Period I to II (Fig. 11), consistent with the increase in smaller particles and CCN. During Period III, there is a brief period of increased concentrations of particles smaller than $58 \mathrm{~nm}$, coincident with a rise in organics (Fig. 10), while sulphate and MSA concentrations remain steady or decrease slightly. The mass distributions during this time show a distinct shoulder mode developing in sulphate at $D_{\mathrm{va}}=370 \mathrm{~nm}$, corresponding to a shift in the organics distribution to smaller sizes, and a smaller mode at $150 \mathrm{~nm}$ developing in sulphate, with a corresponding developing mode in organics (Fig. 11). Concentrations of organics increase slightly to $0.6 \mu \mathrm{g} \mathrm{m}^{-3}$, while sulphate has decreased to $0.84 \mu \mathrm{g} \mathrm{m}^{-3}$. Period IV is characterized by increases in the organic and sulphate mass concentrations. During this time, particles with diameters less than $200 \mathrm{~nm}$ increase while particles smaller than $58 \mathrm{~nm}$ decrease (Fig. 10), and the developing small mode at $150 \mathrm{~nm}$ is more prominent in sulphate, MSA, and especially organics while the shoulder mode at $380 \mathrm{~nm}$ remains (Fig. 11). Period V is characterized by an increase in particles with diameters greater than $86 \mathrm{~nm}$, and an increase in $\mathrm{CCN}_{0.34 \%}$. The 

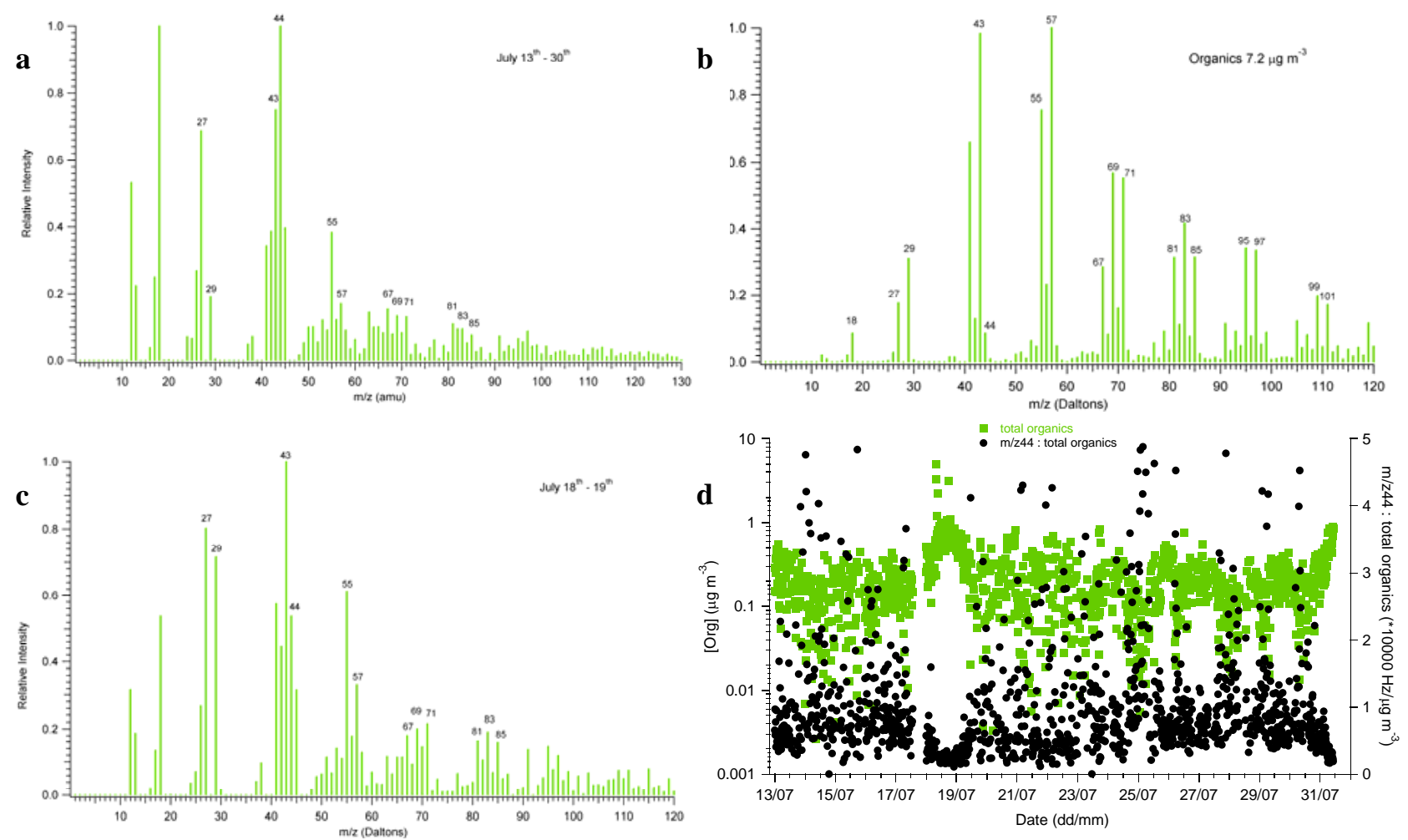

Fig. 9. Mass spectra of organics, plotted as relative intensity, (a) for the entire sample period, excluding ship plumes and the 18 July case, (b) during direct fumigation by ship exhaust (Phinney et al., 2006), and (c) for the period of high organics mass concentration, 18 July. Plot (d) shows the total mass concentration of organics (left y-axis; log scale) and the ratio of the voltage intensity of the signal at $\mathrm{m} / z 44$ to total organic mass for 18 July (“ $\mathrm{m} / \mathrm{z}$ 44:total”; right y-axis), after periods of direct fumigation are removed. The ratio depicts the relative amount of oxygenated organics in the air; on 18 July a reduction in the ratio and in the scatter of the values is evident indicating a relatively less oxygenated organic and a distinct source.

organic is relatively constant throughout the period, but it is three times higher in Period V $\left(0.92 \mu \mathrm{g} \mathrm{m}^{-3}\right)$ relative to Periods I and II, and sulphate is also higher in Period V $\left(1.36 \mu \mathrm{g} \mathrm{m}^{-3}\right)$. The mass distribution in Period V shows the small mode that had developed at $150 \mathrm{~nm}$ has grown to a modal diameter of $180 \mathrm{~nm}$ as the mass concentration increases, and the shoulder mode at $380 \mathrm{~nm}$ has combined with the dominant mode to make a single mode at $500 \mathrm{~nm}$. Finally, in Period VI the concentration of organics decreases to $0.68 \mu \mathrm{g} \mathrm{m}^{-3}$ while the sulphate concentration increases and then decreases, and $\mathrm{CCN}_{0.19 \%}$ increase. The size spectrum of the sulphate (Fig. 11) shows it is returning to a monomodal distribution with a modal diameter of $500 \mathrm{~nm}$, but is still skewed towards smaller sizes compared with Period I.

The progression from Periods I through VI indicates an evolution of the aerosol from an internal mixture of organic and sulphate in Period I to a more external organic-sulphate mixture in Period's II through IV with more organic mass at smaller sizes, and finally shifting in Periods V and VI to a more internal mix of organics and sulphate with fewer smaller particles and less mass at smaller sizes, and more larger CCN. It is evident that during Periods III and IV there are different mixes of organics and sulphate. By Period V, sulphate and organics have similar distributions, except below $100 \mathrm{~nm} D_{\text {va. }}$.

The increase in particle number concentrations shown in Fig. 7c, which occurs largely during this 18 July time period, is attributed to the presence of the organics. These observations lend support to the hypothesis that, in the presence of biogenic sulphur, the smaller organic particles from diffuse ship emissions act as condensation sites for the sulphate and MSA, eventually returning the aerosol to an internal mix of organics, MSA and sulphate. The hypothesis is investigated further below.

\subsubsection{Organics and $\mathrm{CCN}$}

In the Monterey Area Ship Track (MAST) experiment off the coast of California, unprocessed diesel emissions were found to be inefficient as CCN due to their hygroscopicity characteristics (Russell et al., 1999), and condensation was found to be the key mechanism responsible for adding sulphate mass to the primary organic emissions. 


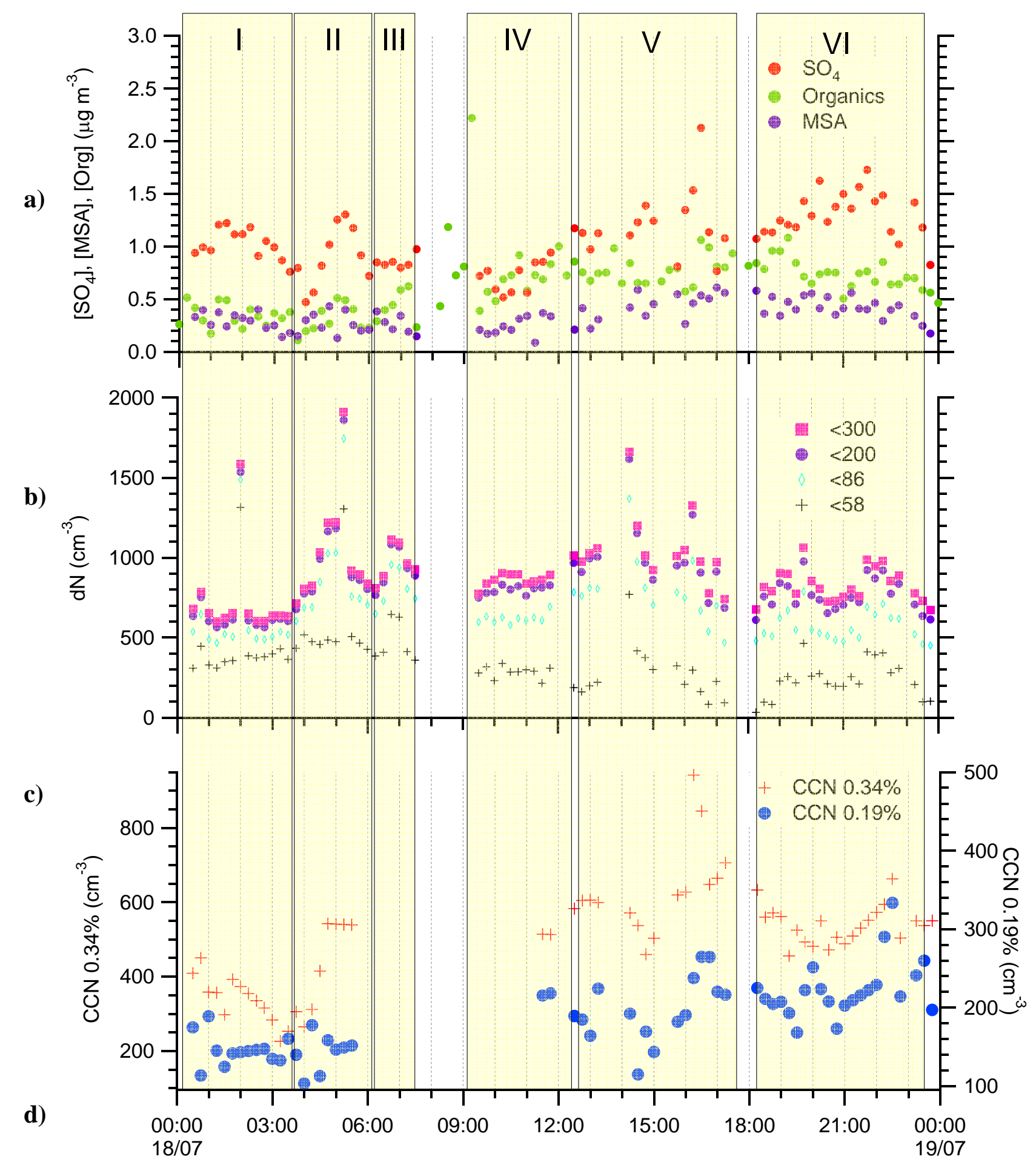

Date and Time in 2002 (PDT; dd/mm hh:mm)

Fig. 10. Expanded view of Fig. 2, centred on the increase in organics mass concentration and number concentration 18 July. The plot is divided into six time intervals: Period I, 00:00-03:45, Period II, 03:45-06:00, Period III, 06:00-07:30, Period IV 09:00-12:30, Period V: 12:30-17:30, and Period VI: 18:00-23:30. 

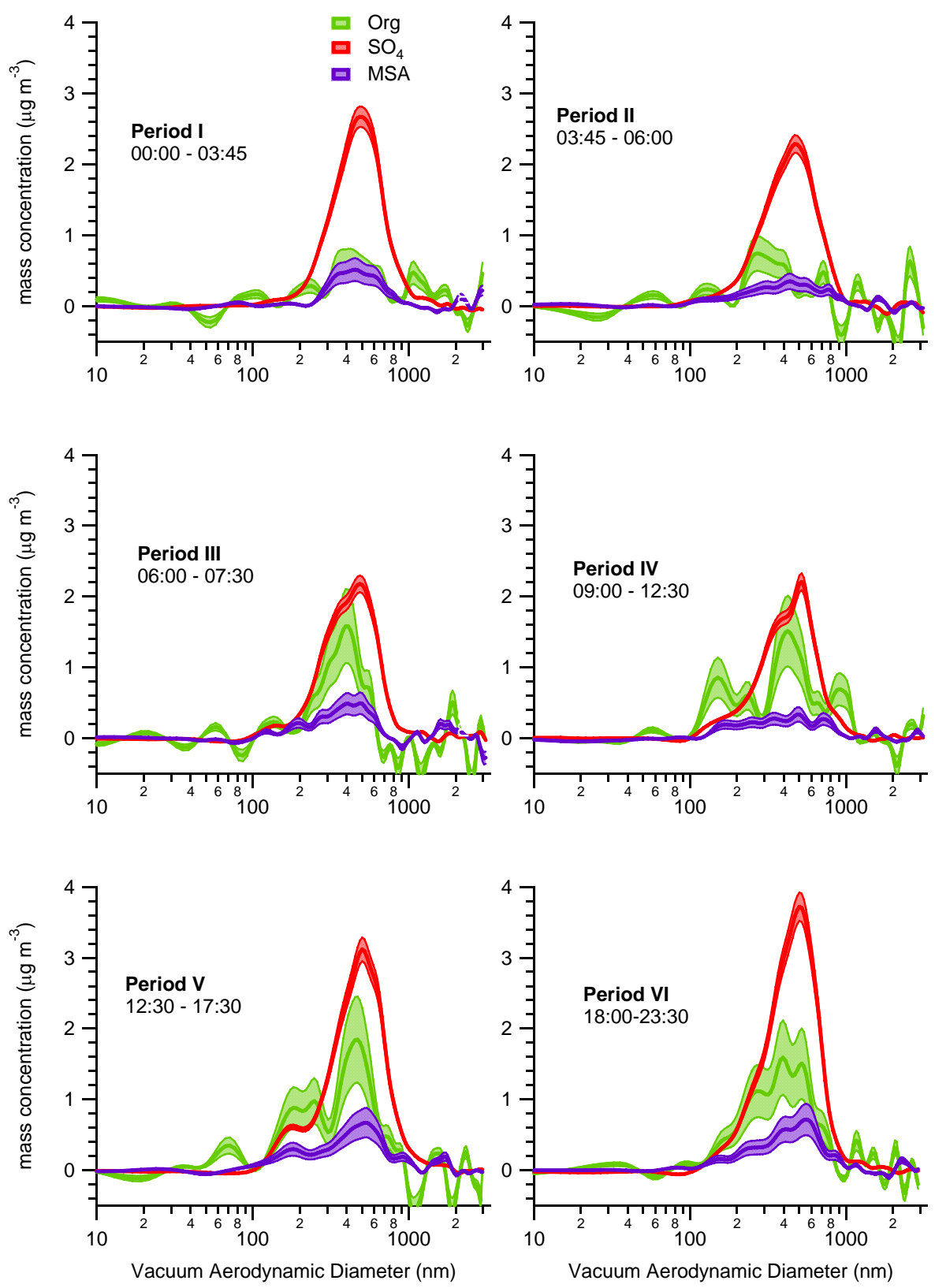

Fig. 11. Evolution of the mass distributions of organics, sulphate, and MSA measured by the Q-AMS 18 July, during Period I, 00:00-03:45, Period II, 03:45-06:00, Period III, 06:00-07:30, Period IV, 09:00-12:30, Period V, 12:30-17:30, and Period VI, 18:00-23:30, plotted against vacuum aerodynamic diameter, $D_{\mathrm{va}}$. The thickness of the Q-AMS curves indicates the uncertainty range.

Figure 10 showed an increase first in smaller CCN $\left(\mathrm{CCN}_{0.34 \%}\right)$ as small organics increased, followed by an increase in larger $\mathrm{CCN}\left(\mathrm{CCN}_{0.19 \%}\right)$ as sulphate and MSA concentrations increased at larger sizes. In Fig. 12a and b, the correlations of organics and of $\left[\mathrm{MSA}+\mathrm{SO}_{4}\right]$ each with $\mathrm{CCN}$ are shown for the entire sample period excluding 18 July. In Fig. 12c and d, the same regressions are shown for the 18 July time period only. The correlation of $\mathrm{CCN}$ with organics throughout the entire study is weak (Fig. 12a), whereas the correlation of $\mathrm{CCN}$ with $\left[\mathrm{MSA}+\mathrm{SO}_{4}\right]$ is much higher (Fig. 12b), indicating that the sulphur species exert some control over the CCN throughout the sample period. For 18 July, however, a different pattern emerges. In this case, the CCN better correlate with organics (Fig. 12c) than with [MSA+SO $\left.\mathrm{S}_{4}\right]$ (Fig. 12d), and those correlations with organics are significantly higher than those for the whole sample period. Thus, over the majority of the study period the CCN are controlled by the MSA and sulphate, but on 18 July when 

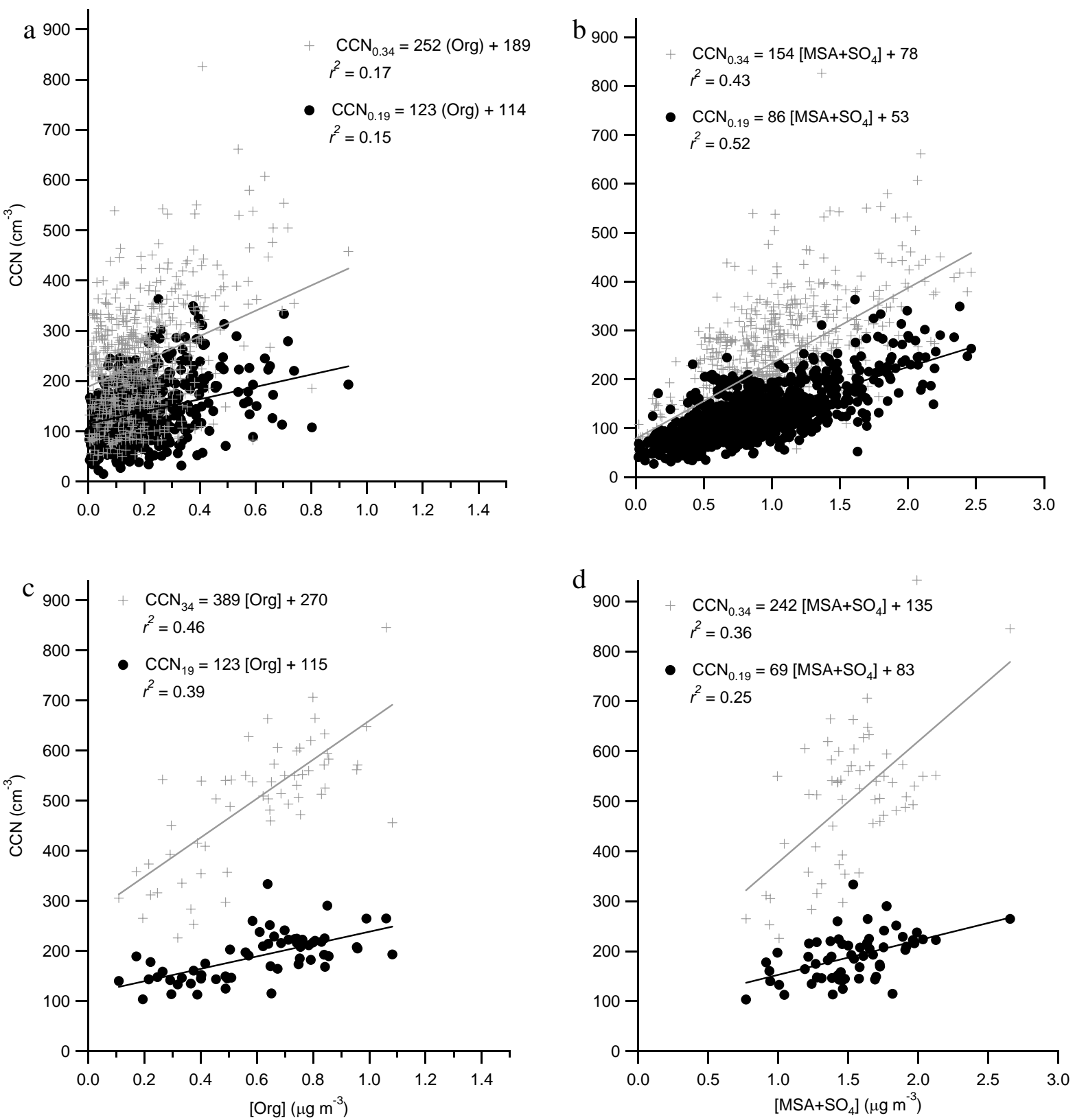

Fig. 12. Correlations of $\mathrm{CCN}$ with mass concentrations of organics and sulphur species: (a) and (b) show the correlation of CCN with organics and with $\left[\mathrm{MSA}+\mathrm{SO}_{4}\right]$, respectively, for the entire sample period excluding $18 \mathrm{July}$; (c) and (d) show the correlations for points on 18 July only. The better correlation in (b) compared with (a) indicates that, in general, the MSA and sulphate control the CCN. However, the improved correlations in (c) compared with (a) indicate that for 18 July the organics exert a stronger control on the CCN, consistent with the results shown in Figs. 10 and 11.

the concentrations of organics increased due to regional ship emissions, these particles exerted more control over the CCN than did the sulphur species. The slope of the regression for $\mathrm{CCN}_{0.34 \%}$ increases by about $50 \%$ during the 18 July time period compared with the rest of the sample period, for both sulphate and organics, indicating that for a given increase in mass concentration there are 50\% more CCN on 18 July than for the rest of the sample period. This difference in slope is not evident for $\mathrm{CCN}_{0.19 \%}$ (larger $\mathrm{CCN}$ ).

It is interesting that the correlation of sulphate with organics during the 18 July time period is relatively weak (Fig. 13a). A close look at Fig. 10 reveals that the sulphate and organics exhibit a similar shape but shifted in time, with sulphate rising after the organics. The correlation between 
a

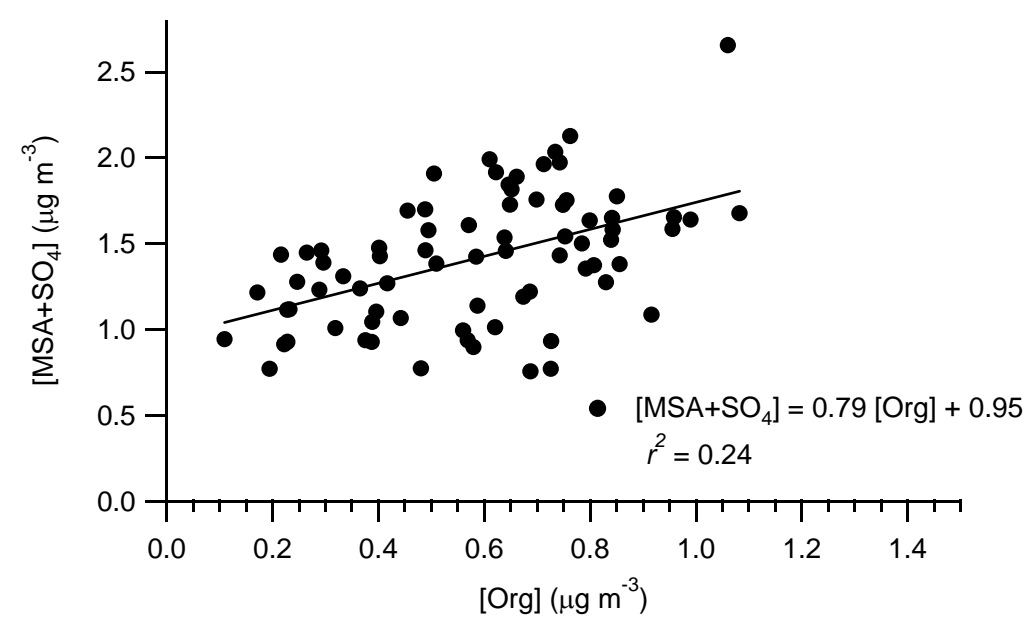

b

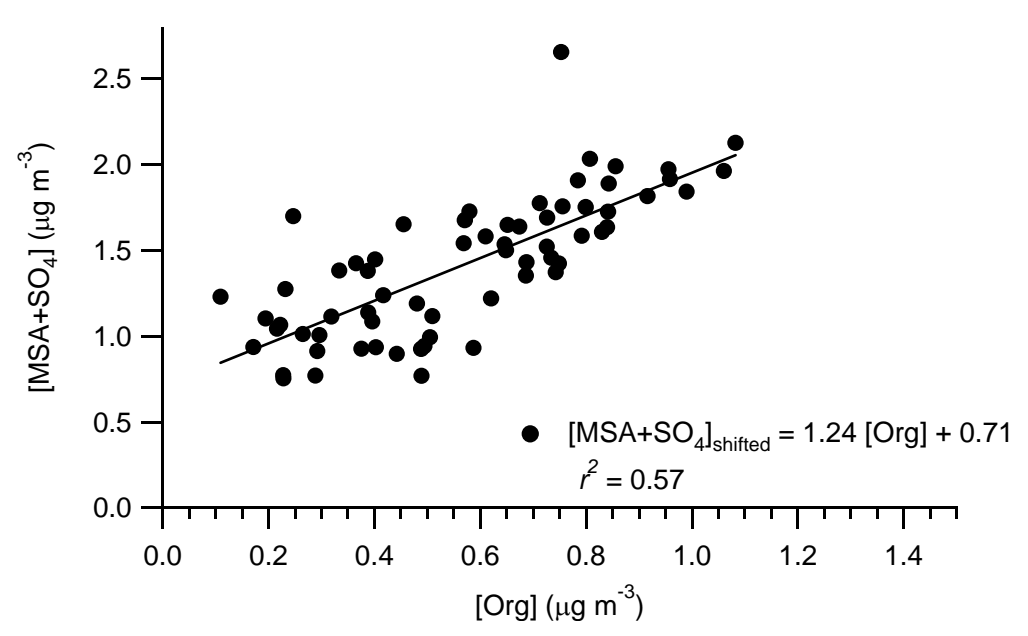

Fig. 13. Correlation of [MSA+SO $\mathrm{S}_{4}$ ] with organics for $18 \mathrm{July.} \mathrm{In} \mathrm{(a)} \mathrm{the} \mathrm{series} \mathrm{are} \mathrm{plotted} \mathrm{directly} \mathrm{against} \mathrm{each} \mathrm{other,} \mathrm{and} \mathrm{show} \mathrm{only} \mathrm{a} \mathrm{weak}$ correlation. In (b) the $\left[\mathrm{MSA}+\mathrm{SO}_{4}\right]$ series is first shifted back in time and then plotted against organics. The best correlation was seen for a time-shift of $2.5 \mathrm{~h}$ (shown here), suggesting that on 18 July the MSA and sulphate condensed onto the organics over a time scale of several hours.

$\left[\mathrm{MSA}+\mathrm{SO}_{4}\right]$ and organics is highest $\left(r^{2}=0.57\right)$ when the sulphate and MSA time series are shifted back by $2.5 \mathrm{~h}$ compared to the organics time series (Fig. 13b). This time delay in MSA and sulphate concentrations requires further investigation, but lends support to the theory that sulphate and MSA condense onto the organics over time, resulting in a delayed increase in their mass concentrations relative to the increase in organic mass.

The influence of organics on CCN for higher mass fractions of organic in the particles has been observed for anthropogenic aerosols (Chang et al., 2007; Wang et al., 2008), suggesting that the organic material can significantly impact the water uptake. However, in the 18 July case water uptake does not appear to be the main role of the organic mass (Shantz et al., 2008), likely because the organic mass fraction was not high enough relative to sulphate. Rather, the higher slopes of $\mathrm{CCN}$ versus $\left[\mathrm{MSA}+\mathrm{SO}_{4}\right]$ for this time period reflect the sulphate and MSA distributing over a larger number of particles (principally primary organic emissions), yielding more $\mathrm{CCN}$ for a given value of $\left[\mathrm{MSA}+\mathrm{SO}_{4}\right]$. Modelling results from Pierce et al. (2007) showing that the addition of insoluble primary organic aerosol increases the concentration of $\mathrm{CCN}$ active at $0.2 \%$ supersaturation by $40-50 \%$ globally due to the ability of organics to act as condensation sites for sulphuric acid, are consistent with these findings. 


\section{Summary and conclusions}

Seasonal relationships have been found between DMS, MSA, and cloud condensation nuclei $(\mathrm{CCN})$ in the marine environment (Ayers and Gras, 1991; Ayers et al., 1991; Andreae et al., 1995), and correlations among sulphate, MSA, and $\mathrm{SO}_{2}$ on a shorter temporal scale are reported in Huebert et al. (1996). In Phinney et al. (2006), DMS and MSA showed anti-correlated behaviour, while anti-correlations in DMS and $\mathrm{SO}_{2}$ are reported elsewhere (i.e. Davis et al., 1999). The variations in these relationships are in part owing to the timescale of sampling. Similarly, in contrast to the findings of Hegg et al. (1991), no correlation between DMS and CCN was found during this study. This is not surprising considering that the timescale for oxidation of DMS is on the order of hours to one day and that our measurements are at 15-min to $1-\mathrm{h}$ resolution. High wind speeds will complicate these relationships over the relatively short timescales and small geographic distribution of our measurements.

With one exception, the baseline CCN concentrations over 18 days were maintained without obvious nucleation events, and several periods of increased CCN were observed without accompanying nucleation events. The one exception was from 14 July. On that day, increased nanoparticle concentrations corresponded to a decrease in gaseous $\mathrm{SO}_{2}$ concentrations that followed a decreased in DMS concentrations. About $6 \mathrm{~h}$ later, an increase in the $\mathrm{CCN}$ was observed. The increase in the $\mathrm{CCN}$ was consistent with the growth and evolution of particle size, linking the $\mathrm{CCN}$ increase back to the oxidation of DMS. The timeframe for nucleation and growth of particles to detectable sizes implies that the DMS source region was $200 \mathrm{~km}-400 \mathrm{~km}$ upwind (to the west) of the sample region.

The most significant results of this paper relate to the interaction between organics and sulphate in the marine environment. Our findings suggest that anthropogenic organics may alter the DMS-sulphate-CCN connection proposed by Shaw (1983) and Charlson et al. (1987), and that biogenic marine organics do not play a large role as $\mathrm{CCN}$ in this environment as in O'Dowd et al. (2004). In general, the CCN observed in this study were significantly correlated with MSA and sulphate, and were not correlated with organic mass concentrations. However, in one case (18 July), an increase in particulate organic mass associated with diffuse regional ship emissions - identified in the Q-AMS measurements by the lower and more stable ratio of $\mathrm{m} / \mathrm{z} 44$ to total organic mass and the relative enhancements of mass fragments at $m / z, 43$ and 57 during this time period as compared with the average fragmentation pattern over the entire study - increased the number concentrations of particles with diameters less than $90 \mathrm{~nm}$, and the MSA and sulphate mass concentrations increased $2-3 \mathrm{~h}$ later. The organics during this time were correlated with $\mathrm{CCN}$ number concentrations, and the evolution of the mass distributions of organics, sulphate and MSA indicate the sulphur species condensed onto the smaller organic particles. Over several hours the aerosol evolved to become more internally-mixed with most particles $>90 \mathrm{~nm}$, and the $\mathrm{CCN}$ concentrations increased. Thus, while the condensation of sulphate and MSA is essential for the activation of the aerosols as $\mathrm{CCN}$, diffused primary emissions of anthropogenic organic particles over the ocean, where present, may have a dominant influence on the number concentrations of particles active at supersaturations typical of marine stratocumuli on a regional scale.

Finally, O'Dowd et al. (2004) suggested that the concentrations of marine biogenic organics in the atmosphere over the Atlantic Ocean are especially high during plankton bloom periods, and discuss implications for the marine biota-aerosol-cloud-climate feedback mechanism. Here we find little support for a role of these particles as $\mathrm{CCN}$, as evidenced by the weak correlation of organics with $\mathrm{CCN}$ over the entire sample period. Rather, our findings point to sulphur compounds and ship-sourced organics together having the greatest impact on CCN over the northeast Pacific Ocean.

\section{Appendix A}

\section{Determination of MSA mass concentrations with the Q-AMS}

Laboratory experiments to determine the fragmentation pattern of methanesulphonic Acid (MSA) were conducted independently at Environment Canada, Downsview, ON, and Aerodyne Research Incorporated, Billerica, MA, May 2003. The signal due to MSA fragments was previously attributed to the fragmentation of sulphate and organics, and as such the sulphate and organics were overestimated and MSA was not diagnosed. The following experiments were designed to determine what portion of certain sulphate, ammonium and organic fragments should be attributed to MSA.

\section{A1 Theory}

Methanesulphonic acid (MSA) has the chemical formula $\mathrm{CH}_{3} \mathrm{SO}_{3} \mathrm{H}$, and molecular weight $96.11 \mathrm{amu} / \mathrm{molecule}$. The chemical structure of MSA is<smiles>CS(=O)(=O)O</smiles>

where the methyl group and hydroxyl group are singlebonded to the $\mathrm{S}$ atom and the oxygen molecules are doublebonded to the $\mathrm{S}$ atom. The MSA molecule, upon flash vaporization and ionization in the vacuum vaporization chamber of the AMS, is expected to fragment at the single bonds C-S and S-OH, yielding fragments at $m / z 15\left(\mathrm{CH}_{3}^{+}\right)$and at $m / z, 17$ $\left(\mathrm{OH}^{+}\right)$. As well, signals at $\mathrm{m} / z 14\left(\mathrm{CH}_{2}^{+}\right), 16\left(\mathrm{CH}_{4}^{+}\right), 31$ $\left(\mathrm{CH}_{3} \mathrm{O}^{+}\right), 48\left(\mathrm{SO}^{+}\right), 64\left(\mathrm{SO}_{2}^{+}\right), 65\left(\mathrm{HSO}_{2}^{+}\right), 78\left(\mathrm{CH}_{2} \mathrm{SO}_{2}^{+}\right)$, $79\left(\mathrm{CH}_{3} \mathrm{SO}_{2}^{+}\right),\left(80\left(\mathrm{SO}_{3}^{+}\right), 81\left(\mathrm{HSO}_{3}^{+}\right)\right.$, and $96\left(\mathrm{MSA}^{+}\right)$ 
Table A1. Solution mixtures and size distribution characteristics of MSA identification trials using the Q-AMS. AmmSul refers to Ammonium Sulphate, MSA to Methansulphonic Acid.

\begin{tabular}{lclccc}
\hline Trial & Run \# & Composition & Number Concentration $\left(\mathrm{cm}^{-3}\right)$ & $\begin{array}{c}\text { Physical Diameter } \\
(\mathrm{nm})\end{array}$ & Plot \\
\hline 1 & 2409 & AmmSul & 5400 & 300 & A1 \\
2 & 4401 & MSA+AmmSul & 500 & 300 & A2 \\
3 & 4396 & MSA & 2000 & 300 & A3,A5 \\
4 & 4403 & $n / a$ & 0 & $n / a$ & A4 \\
\hline
\end{tabular}

may be expected. The NIST spectrum for MSA consists of highest peaks at $m / z 96,79,81,78,31,65$, and 48 , in decending order of intensity (NIST, 2005).

\section{A2 Experimental setup}

The Q-AMS was connected downflow of an atomizer generating a polydisperse aerosol population from a dilute solution. In between the atomizer and the Q-AMS was placed a silica cartridge for drying the particles leaving the atomizer, and a TSI Scanning Mobility Particle Sizer (SMPS; Model 3071 Electrostatic Classifier and a Model 3025 Ultrafine Condensation Particle Counter), which selects a monodisperse aerosol population from the polydisperse aerosol generated by the atomizer.

\section{A3 Procedure}

Solutions of pure ammonium sulphate $\left(\left(\mathrm{NH}_{4}\right)_{2} \mathrm{SO}_{4}\right)$, pure $\mathrm{MSA}$, and a mixture of MSA and $\left(\mathrm{NH}_{4}\right)_{2} \mathrm{SO}_{4}$ were diluted to a concentration of $\sim 0.01 \mathrm{M}$ using de-ionized water (DIW).

The Q-AMS was calibrated to ensure optimal performance: the electron multiplier was calibrated for the gain, and then a mass calibration was done to determine the ionization efficiency of nitrate, a standard calibration procedure for the Q-AMS.

Particles were generated by atomizing the solutions of MSA and ammonium sulphate, and the particles were measured by the Q-AMS in mass spectrum mode to obtain a relative mass spectrum from which to create a fragmentation pattern for MSA, and then in time-of-flight mode to determine the ionization efficiency of MSA. Table A1 describes the solution mixtures and size distribution characteristics of the trials.

\section{A3.1 Pure $\left(\mathrm{NH}_{4}\right)_{2} \mathrm{SO}_{4}$ solution}

A $0.01 \mathrm{M}$ solution of $\left(\mathrm{NH}_{4}\right)_{2} \mathrm{SO}_{4}$ was placed in the atomizer bottle and sampled by the AMS. A mass spectrum was obtained, shown in Fig. A1. Peaks attributed to $\mathrm{NH}_{4}^{+}$fragmentation are observed at $m / z, 15,16$, and 17, and peaks attributed to $\mathrm{SO}_{4}^{2+}$ fragmentation are observed at $m / z, 18,32,48,64,80$, 81 , and 98 . The mass fragment at $m / z, 18$ is due to remnant
$\mathrm{H}_{2} \mathrm{O}$ present on the ammonium sulphate particles, and relative humidity within the instrument.

\section{A3.2 $\mathrm{MSA}+\left(\mathrm{NH}_{4}\right)_{2} \mathrm{SO}_{4}$ solution}

The atomizer bottle was rinsed with DIW and filled with a $0.01 \mathrm{M}$ solution of MSA and $\left(\mathrm{NH}_{4}\right)_{2} \mathrm{SO}_{4}$. The mass spectrum obtained by the AMS is shown in Fig. A2. Peaks attributed to ammonium are observed at $m / z 15,16$ and 17 , and peaks attributed to sulphate are observed at $m / z$ 32, 48, 64, $65,80,81$, and 98 . Peaks attributed to organics in this batch file are observed at $m / z, 12,13,15,29,44,45,64,65,78$, 79 , and 96. Because we have not included organics in our atomized solution, these peaks, along with a portion of those diagnosed here as sulphate, are likely due to the fragmentation of MSA.

\section{A3.3 Pure MSA solution}

A pure $0.001 \mathrm{M}$ MSA solution was atomized and $300 \mathrm{~nm}$ particles were selected with the DMA. The mass spectra are shown in Fig. A3. All of the MSA is attributed to sulphate and organics; peaks are observed at $\mathrm{m} / \mathrm{z} 15,16,29,31,48$, 64, 65, 78, 79, 81, and 96 .

Figure A4 shows the mass spectrum when the DMA was adjusted to $0 \mathrm{~V}$, meaning no particles should enter the QAMS.

\section{A4 Results}

Figures A1 through A3 show the mass spectrum obtain through each of the solution trials. These plots were analysed with the previous version of the fragmentation file, which did not include MSA fragmentation (Allan et al., 2004), thus all MSA is attributed to sulphate and organic fragmentation. After examination of these plots, the fragment $m / z, 79$ was used as the basis for the identification of MSA because there is no contribution to this fragment from ammonium sulphate or sulphuric acid, but a strong signal is detected when measuring MSA. Fragments 15, 29, 31, 45, 65, and 78 were also identified through the fragmentation pattern as having contributions from MSA, and were calculated in relation to the signal at $m / z, 79$. In this way, a fragmentation table for 
Table A2. Fragmentation table resulting from controlled laboratory trials running atomized Ammonium Sulphate and MSA through the Q-AMS. MSA fragments are based on the fragments at $\mathrm{m} / z 79$ and 96 . Fragments whose formulas have been modified from the previous version of the fragmentation table (Allan et al., 2004) are noted in boldface.

\begin{tabular}{|c|c|c|c|}
\hline$m / z$ & frag_msa & frag_sulphate & frag_organic \\
\hline \multicolumn{4}{|l|}{1} \\
\hline \multicolumn{4}{|l|}{2} \\
\hline \multicolumn{4}{|l|}{3} \\
\hline \multicolumn{4}{|l|}{4} \\
\hline \multicolumn{4}{|l|}{5} \\
\hline \multicolumn{4}{|l|}{6} \\
\hline \multicolumn{4}{|l|}{7} \\
\hline \multicolumn{4}{|l|}{8} \\
\hline \multicolumn{4}{|l|}{9} \\
\hline \multicolumn{4}{|l|}{10} \\
\hline \multicolumn{4}{|l|}{11} \\
\hline 12 & & & 12 \\
\hline \multicolumn{4}{|r|}{13} \\
\hline \multicolumn{4}{|l|}{14} \\
\hline 15 & $2.16 *$ frag_msa[79],2.16*frag_msa[96] & & 15,-frag_NH4[15],-frag_air[15],-frag_msa[15] \\
\hline 16 & & frag_SO3[16] & $0.04 *$ frag_organic $[18]$ \\
\hline 17 & & frag_SO3[17] & $0.25 *$ frag_organic $[18]$ \\
\hline 18 & & frag_SO3[18] & $1 *$ frag_organic $[44]$ \\
\hline 19 & & frag_SO3[19] & $0.000691 *$ frag_organic $[18], 0.002 *$ frag_organic $[17]$ \\
\hline 20 & & frag_SO3[20] & $0.002 *$ frag_organic $[18]$ \\
\hline \multicolumn{4}{|r|}{ 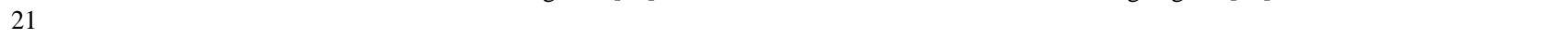 } \\
\hline \multicolumn{4}{|l|}{22} \\
\hline \multicolumn{4}{|l|}{23} \\
\hline 24 & & frag_SO3[24],frag_H2SO4[24] & 24,-frag_sulphate[24] \\
\hline 25 & & & 25 \\
\hline 26 & & & 26 \\
\hline 27 & & & 27 \\
\hline \multicolumn{4}{|l|}{28} \\
\hline 29 & $0.22 *$ frag_msa[79],0.22*frag_msa[96] & & 29,-frag_air[29],-frag_msa[29] \\
\hline 30 & & & $0.022 *$ frag_organic $[29]$ \\
\hline 31 & $0.51 *$ frag_msa[79],0.51*frag_msa[96] & & \\
\hline 32 & $0.17 *$ frag_msa[79] & frag_SO3[32],frag_H2SO4[32],-frag_msa[32] & \\
\hline 33 & & frag_SO3[33],frag_H2SO4[33] & \\
\hline 34 & & frag_SO3[34],frag_H2SO4[34] & \\
\hline \multicolumn{4}{|c|}{ 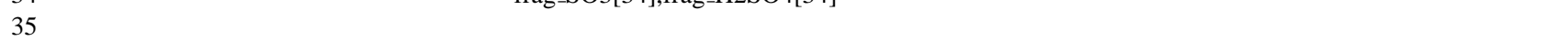 } \\
\hline \multicolumn{4}{|l|}{36} \\
\hline 37 & & & 37,-frag_chloride[37] \\
\hline \multicolumn{4}{|r|}{ 38,-frag_chloride[38],-frag_air[38] } \\
\hline \multicolumn{4}{|r|}{ 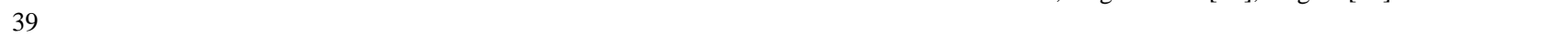 } \\
\hline \multicolumn{4}{|l|}{40} \\
\hline 41 & & & 41,-frag_K[41] \\
\hline 42 & & & 42 \\
\hline 43 & & & 43 \\
\hline 44 & & & 44,-frag_air[44] \\
\hline 45 & $0.23 *$ frag_msa[79],0.23*frag_msa[96] & & 45,-frag_msa[45] \\
\hline 46 & & & \\
\hline 47 & & & \\
\hline 48 & $0.64 *$ frag_msa[79] & frag_SO3[48],frag_H2SO4[48],-frag_msa[48] & $0.5 *$ frag_organic $[62]$ \\
\hline 49 & & frag_SO3[49],frag_H2SO4[49] & 49,-frag_sulphate[49] \\
\hline
\end{tabular}


Table A2. Continued.

\begin{tabular}{|c|c|c|c|}
\hline$m / z$ & frag_msa & frag_sulphate & frag_organic \\
\hline 50 & & frag_SO3[50],frag_H2SO4[50] & 50,-frag_sulphate[50] \\
\hline 51 & & & 51 \\
\hline 52 & & frag_SO3[52],frag_H2SO4[52] & 52,-frag_sulphate[52] \\
\hline 53 & & & 53 \\
\hline 54 & & & 54 \\
\hline 55 & & & 55 \\
\hline 56 & & & 56 \\
\hline 57 & & & 57 \\
\hline 58 & & & 58 \\
\hline 59 & & & 59 \\
\hline 60 & & & 60 \\
\hline 61 & & & 61 \\
\hline 62 & & & 62 \\
\hline 63 & & & 63,-frag_nitrate[63] \\
\hline 64 & $0.45 *$ frag_msa[79] & frag_SO3[64],frag_H2SO4[64],-frag_msa[64] & frag_organic[50] \\
\hline 65 & $0.37 *$ frag_msa[79],0.37*frag_msa[96] & frag_SO3[65],frag_H2SO4[65],-frag_msa[65] & frag_organic[51] \\
\hline 66 & & frag_SO3[66],frag_H2SO4[66] & 66,-frag_sulphate[66] \\
\hline 67 & & & 67 \\
\hline 68 & & & 68 \\
\hline 69 & & & 69 \\
\hline 70 & & & 70 \\
\hline 71 & & & 71 \\
\hline 72 & & & 72 \\
\hline 73 & & & 73 \\
\hline 74 & & & 74 \\
\hline 75 & & & 75 \\
\hline 76 & & & 76 \\
\hline 77 & & & 77 \\
\hline 78 & $0.24 *$ frag_msa[79],0.24*frag_msa[96] & & 78,-frag_msa[78] \\
\hline 79 & 79,-frag_organic[79] & & frag_organic[93] \\
\hline 80 & $0.047 *$ frag_msa[79] & frag_SO3[80],frag_H2SO4[80],-frag_msa[80] & $0.75 *$ frag_organic $[94]$ \\
\hline 81 & $0.53 *$ frag_msa[79] & frag_H2SO4[81],-frag_msa[81] & $0.5 *$ frag_organic[67], $0.5 *$ frag_organic $[95]$ \\
\hline 82 & & frag_SO3[82],frag_H2SO4[82] & 82,-frag_sulphate[82] \\
\hline 83 & & frag_H2SO4[83] & 83 ,-frag_sulphate[83] \\
\hline 84 & & frag_SO3[84],frag_H2SO4[84] & 84,-frag_sulphate[84] \\
\hline 85 & & frag_H2SO4[85] & 85 ,-frag_sulphate[85] \\
\hline 86 & & & 86 \\
\hline 87 & & & 87 \\
\hline 88 & & & 88 \\
\hline 89 & & & 89 \\
\hline 90 & & & 90 \\
\hline 91 & & & 91 \\
\hline 92 & & & 92 \\
\hline 93 & & & 93 \\
\hline 94 & & & 94 \\
\hline 95 & & & 95 \\
\hline 96 & 96,-frag_organic[96] & & $0.5 *$ frag_organic $[110], 0.5 *$ frag_organic $[82$ \\
\hline 97 & & & 97 \\
\hline 98 & & frag_H2SO4[98] & $0.5 *$ frag_organic $[84], 0.5 *$ frag_organic $[112$ \\
\hline 99 & & frag_H2SO4[99] & 99,-frag_sulphate[99] \\
\hline 100 & & frag_H2SO4[100] & 100 ,-frag_sulphate[100] \\
\hline
\end{tabular}




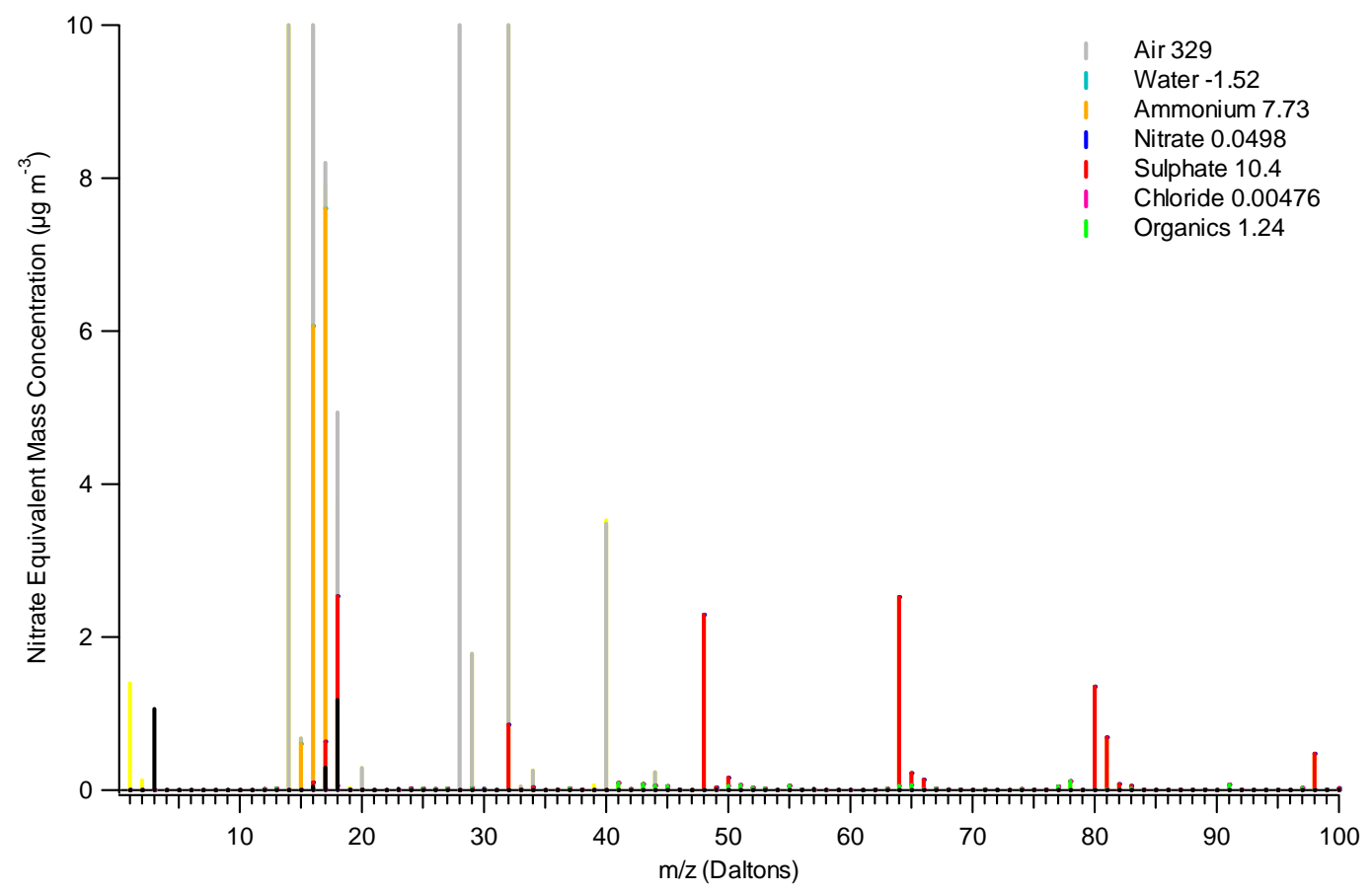

Fig. A1. Q-AMS mass spectrum for trial 1, $\left(\mathrm{NH}_{4}\right)_{2} \mathrm{SO}_{4} 5400$ particles $\mathrm{cm}^{-3}$ at $300 \mathrm{~nm}$ physical diameter.

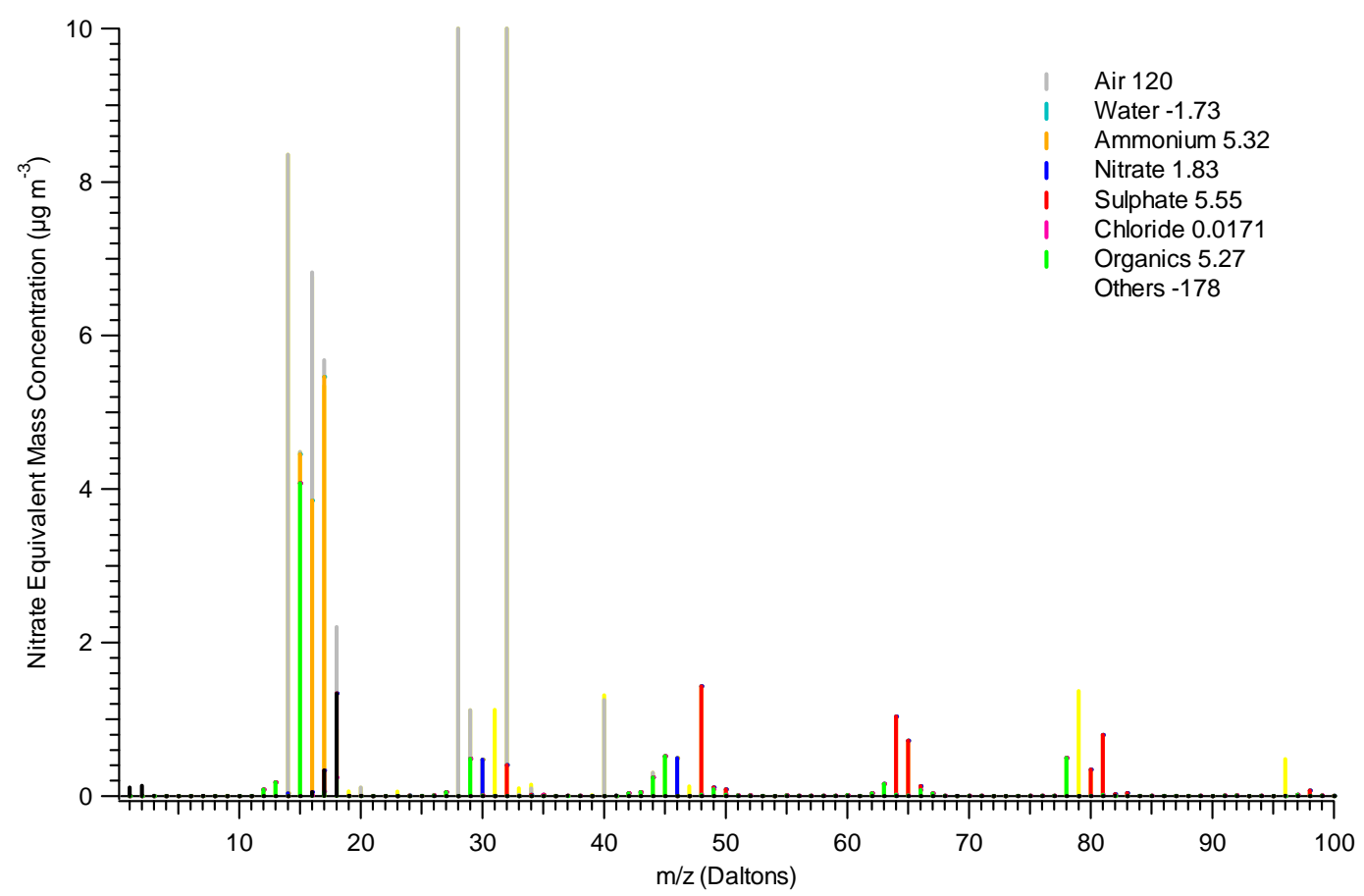

Fig. A2. Q-AMS mass spectrum for trial 2, MSA+( $\left(\mathrm{NH}_{4}\right)_{2} \mathrm{SO}_{4} 500$ particles $\mathrm{cm}^{-3}$ at $300 \mathrm{~nm}$ physical diameter, processed with the previous version of the fragmentation table (which does not analyse for MSA.) 


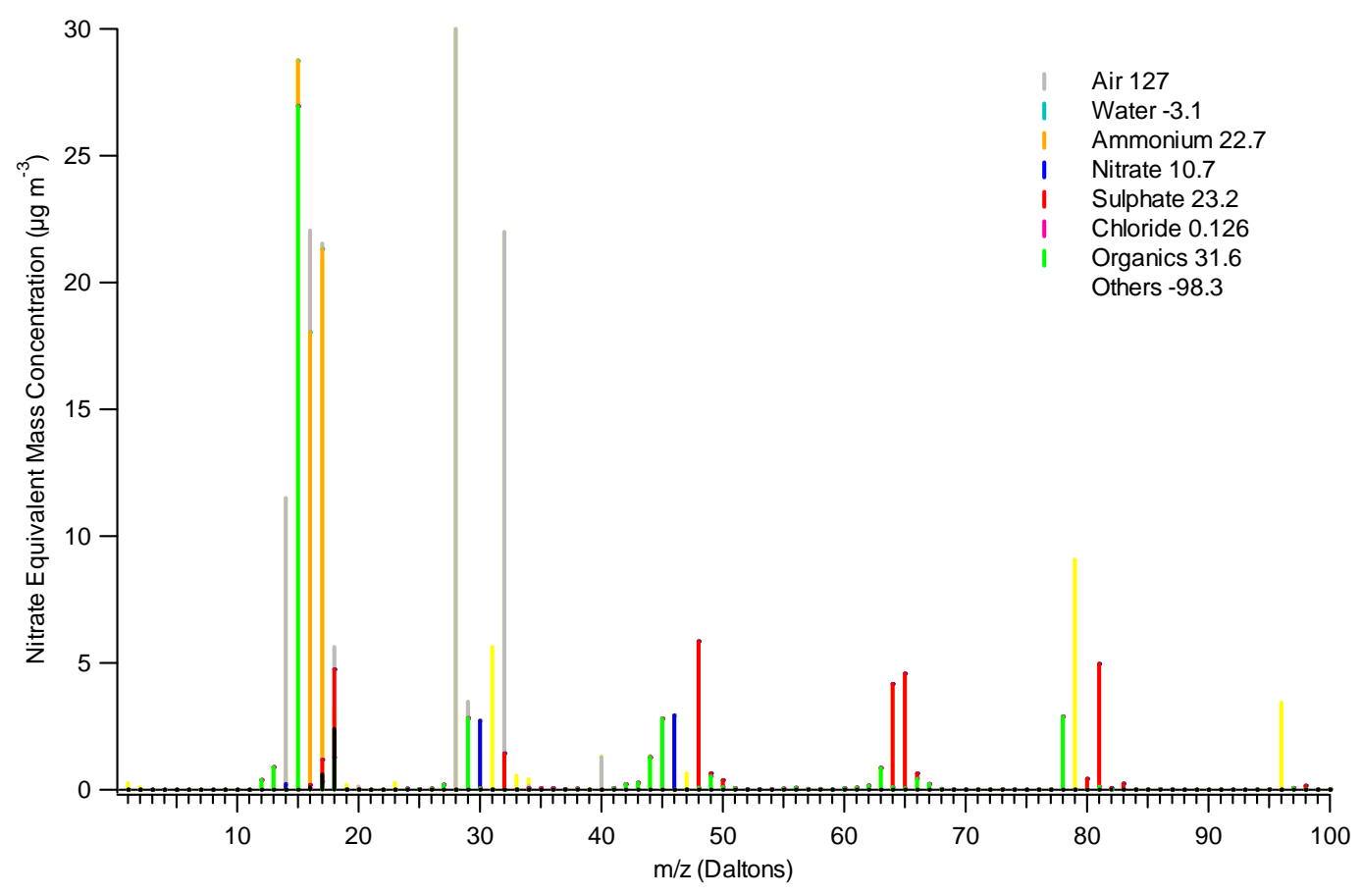

Fig. A3. Q-AMS mass spectrum for trial 3, MSA 2000 particles $\mathrm{cm}^{-3}$ at $300 \mathrm{~nm}$ physical diameter, processed with the previous version of the fragmentation table (which does not analyse for MSA.)

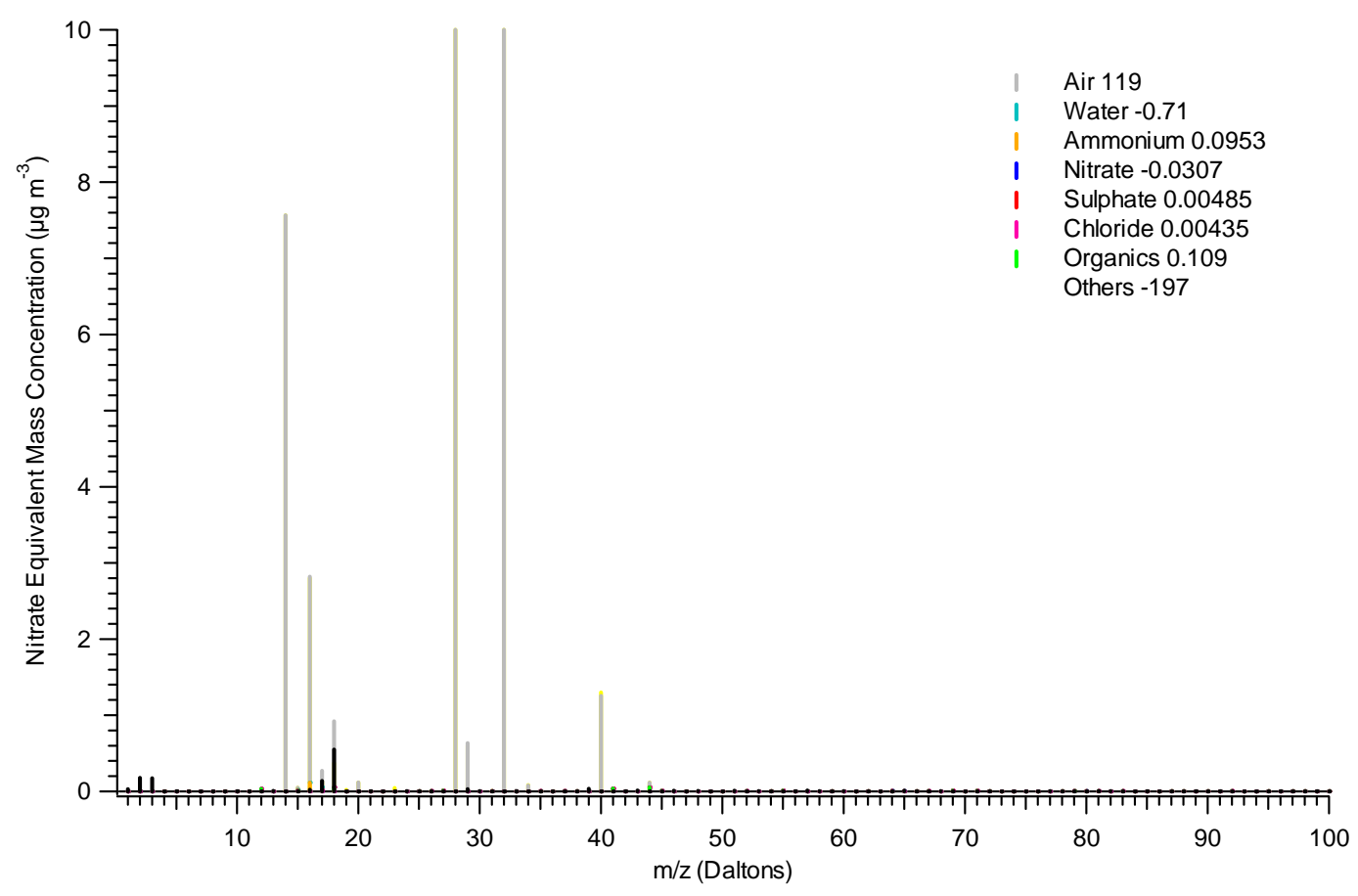

Fig. A4. Q-AMS mass spectrum for trial 4, 0 particles $\mathrm{cm}^{-3}$. 


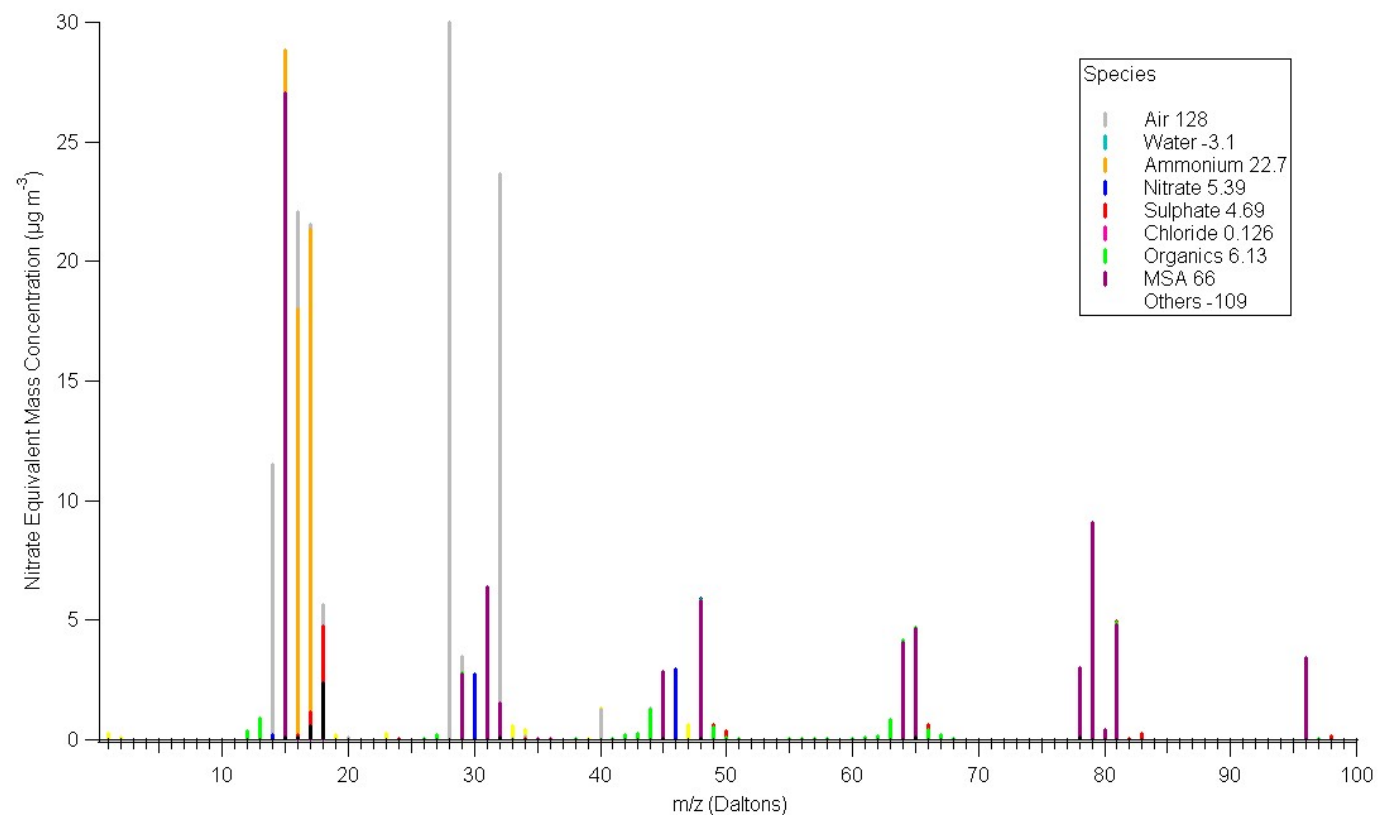

Fig. A5. Q-AMS mass spectrum for trial 3, MSA 2000 particles $\mathrm{cm}^{-3}$ at $300 \mathrm{~nm}$ physical diameter, processed with the new fragmentation table which includes MSA. Note that organics and sulphate masses have decreased compared with Fig. A3, due to the MSA fragments that were previously attributed to sulphate and organics now identified as MSA.

MSA was developed and incorporated into the analysis of the SERIES data, enabling the identification of MSA.

The fragmentation table resulting from this procedure is given in Table A2. Fragments whose determinations have been modified from the previous version of the fragmentation table (Allan et al., 2004), as well as the new MSA fragments, have been noted in boldface. Figure A5 shows the resultant mass spectrum of MSA after analysing the data displayed in Fig. A3 with the new fragmentation table. MSA is shown in purple, and its identification results in a reduction in the previously estimated concentrations of sulphate and organics, since all the mass that is now attributed to MSA was attributed to these species under the previous fragmentation table.

This new fragmentation table has been used to analyse all the Q-AMS data presented in this paper. A previous version of the fragmentation was used to analyse this same QAMS data in Phinney et al. (2006), and resulted in a $13 \%$ underestimation in MSA concentrations. This underestimation has been corrected here, and though the Q-AMS MSA and sulphate measurements were in good agreement with MOUDI filter concentrations and estimated mass based on aerosol physical properties in that paper, the improvement in the fragmentation table results in better agreement. Further independent experiments conducted at Aerodyne Research, Incorporated obtained a mass spectrum of MSA that showed excellent agreement with our laboratory results.
Acknowledgements. The authors thank Julia Marshall, Steve Bacic, Armand Gaudenzi, John Jayne, Hacene Boudries, Desiree Toom-Sauntry, Dave Halpin, Sangeeta Sharma and the captain, crew and fellow scientists of El Puma for help with data collection and analysis. The DMS data presented in this paper was collected by Moire Wadleigh and Carolyn Burridge. L. Langley extends appreciation to the Meteorological Service of Canada - Atlantic and to the anonymous reviewers whose insightful comments improved this manuscript. This work was funded by the joint NSERC/CFCAS project SOLAS and by Environment Canada; N. Shantz was supported in part by an NSERC PGS-B research scholarship.

Edited by: N. Mihalopoulos

\section{References}

Agrawal, H., Malloy, Q. G. J., Welch, W. A., Miller, J. W., and Cocker III, D. R.: In-use gaseous and particulate matter emissions from a modern ocean going container vessel, Atmos. Environ., 42, 5504-5510, 2008.

Albrecht, B. A.: Aerosols, Cloud Microphysics, and Fractional Cloudiness, Science, 245, 1227-1230, 1989.

Allan, J. D., Jimenez, J. L., Williams, P. I., Alfarra, M. R., Bower, K. N., Jayne, J. T., Coe, H., and Worsnop, D. R.: Quantitative sampling using an Aerodyne aerosol mass spectrometer, 1. Techniques of data interpretation and error analysis, J. Geophys. Res., 108, 4090-4100, 2003.

Allan, J. D., Delia, A. E., Coe, H., Bower, K. N., Alfarra, M. R., Jimenez, J. L., Middlebrook, A. M., Drewnick, F., Onasch, T. B., Canagaratna, M. R., Jayne, J. T., and Worsnop, D. R.: 
A generalised method for the extraction of chemically resolved mass spectra from Aerodyne aerosol mass spectrometer data, J. Aerosol Sci., 35, 909-922, 2004.

Andreae, M. O., Elbert, W., Cai, Y., Andreae, T. W., and Gras, J.: Non-sea salt sulfate, methanesulfonate, and nitrate aerosol concentrations and size distributions at Cape Grim, Tasmania, J. Geophys. Res., 104, 21695-21706, 1999.

Andreae, M. O., Elbert, W., and de Mora, S. J.: Biogenic sulfur emissions and aerosols over the tropical South Atlantic, 3. Atmospheric dimethylsulfide, aerosols and cloud condensation nuclei, J. Geophys. Res., 100, 11335-11356, 1995.

Arinami, K. and Tsunogai, S.: Seasonal and regional comparison of oceanic and atmospheric dimethyl sulphide in the northern North Pacific: dilution effects on its concentration during the winter, J. Geophys. Res., 109, 4288, doi:10.1029/2003JD004288, 2004.

Ayers, G. P., Ivey, J. P., and Gillett, R. W.: Coherence between seasonal cycles of dimethyl sulphide, methanesulphonate, and sulphate in marine air, Lett. Nat., 349, 404-406, 1991.

Ayers, G. P. and Gras, J. L.: Seasonal relationship between cloud condensation nuclei and aerosol methanesulphonate in marine air, Lett. Nat., 353, 834-835, 1991

Berresheim, H., Andreae, M. O., Ayers, G. P., Gillet, R. W., Merrill, J. T., Davis, V. J., and Chameides, W. L.: Airborne measurements of dimethylsulfide, sulphur dioxide, and aerosol ions over the southern ocean south of Australia, J. Atmos. Chem., 10(3), 341370, 1990.

Berresheim, H., Elste, T., Tremmel, H. G., Allen, A. G., Hansson, H.-C., Rosman, K., Dal Maso, M., Makela, J. M., Kulmala, M., and O'Dowd, C. D.: Gas-aerosol relationships of $\mathrm{H}_{2} \mathrm{SO}_{4}$, MSA, and $\mathrm{OH}$ : Observations in the coastal marine boundary layer at Mace Head, Ireland, J. Geophys. Res., 107(D19), 8100, doi:10.1029/2000JD000229, 2002.

Boyd, P. W., Law, C. S., Wong, C. S., Nojiri, Y., Tsuda, A., Levasseur, M., Takeda, S., Rivkin, R., Harrison, P. J., Strzepek, R., Gower, J., McKay, R. M., Abraham, E., Arychuk, M., BarwellClarke, J., Crawford, W., Hale, M., Harada, K., Johnson, K., Kiyosawa, H., Kudo, I., Marchetti, A., Miller, W., Needoba, J., Nishioka, J., Ogawa, H., Page, J., Robert, M., Saito, H., Sastri, A., Sherry, N., Soutar, T., Sutherland, N., Taira, Y., Whitney, F., Wong, S.-K. E., and Yoshimura, T.: The decline and fate of an iron-induced subarctic phytoplankton bloom, Nature, 428, 549553, 2003.

Buzorius, G., McNaughtonm, C. S., Clarke, A. D., Covert, D. S., Blomquist, B., Nielsen, K., and Brechtel, F. J.: Secondary aerosol formation in continental outflow conditions during ACEAsia, J. Geophys. Res., 109, 4749, doi:10.1029/2004JD004749, 2004.

Canagaratna, M. R., Jayne, J. T., Ghertner, D. A., Herndon, S., Shi, Q., Jimenez, J. L., Silva, P. J., Williams, P., Lanni, T., Drewnick, F., Demerjian, K. L., Kolb, C. E., and Worsnop, D. R.: Chase Studies of Particulate Emissions from in-use New York City Vehicles, Aerosol. Sci. Tech., 38, 555-573, 2004.

Capaldo, K., Corbett, J. J., Kasibhatla, P., Fischbeck, P., and Pandis, S. N.: Effects of ship emissions on sulphur cycling and radiative climate forcing over the ocean, Nature, 400, 743-746, doi:10.1038/23438, 1999.

Chang, R. Y.-W., Liu, P. S. K., Leaitch, W. R., and Abbatt, J. P. D.: Comparison Between Measured and Predicted CCN Concentrations at Egbert, Ontario: Focus on the Organic Aerosol Fraction,
Atmos. Environ. 41, 8172-8182, 2007.

Charlson, R. J., Lovelock, J. E., Andreae, M. O., and Warren, S. G.: Oceanic phytoplankton, atmospheric sulphur, cloud albedo, and climate, Nature, 326, 655-661, 1987.

Clarke, A. D., Davis, D., Kapustin, V. N., Eisele, F., Chen, G., Paluch, I., Lenschow, D., Bandy, A. R., Thorton, D., Moore, K., Mauldin, L., Tanner, D., Litchy, M., Carroll, M. A., Collins, J., and Albercook, G.: Particle Nucleation in the Tropical Boundary Layer and its Coupling to Marine Sulfur Sources, Science, 282, 89-92, 1998.

Corbett, J. J. and Fischbeck, P. S.: Emissions from ships, Science, 278, 823-824, 1997.

Covert, D. S., Kapustin, V. N., Quinn, P. K., and Bates, T. S.: New particle formation in the marine boundary layer, J. Geophys. Res., 97, 20581-20589, 1992.

Davis, D., Chen, G., Bandy, A., Thornton, D., Eisele, F., Mauldin, L., Tanner, D., Lenschow, D., Fuelberg, H., Huebert, B., Heath, J., Clarke, A., and Blake, D.: Dimethyl sulphide oxidation in the equatorial Pacific: Comparison of model simulations with field observations for DMS, $\mathrm{SO}_{2}, \mathrm{H}_{2} \mathrm{SO}_{4}(\mathrm{~g}), \mathrm{MSA}(\mathrm{g}), \mathrm{MS}$ and NSS, J. Geophys. Res. 104, 5765-5784, 1999.

DeCarlo, P., Slowik, J. G., Worsnop, D. R., Davidovits, P., and Jimenez, J. L.: Particle morphology and density characterization by combined mobility and aerodynamic diameter measurements, Part 1: Theory, Aerosol Sci. Tech. 38, 1185-1205, 2004.

de Oliveira, J. C. P. and Vali, G.: Calibration of a photoelectric cloud condensation nucleus counter, Atmos. Res., 38, 237-248, 1995.

Furutani, H., Dall'Osto, M., Roberts, G. C., and Prather, K. A.: Assessment of the relative importance of atmospheric aging on $\mathrm{CCN}$ activity derived from field observations, Atmos. Environ., 42(13), 3130-3142, 2008.

Hegg, D. A., Radke, L. R., and Hobbs, P. V.: Measurements of Aitken nuclei and cloud condensation nuclei in the marine atmosphere and their relation to the DMS-cloud-climate hypothesis, J. Geophys. Res., 96, 18727-18773, 1991.

Hobbs, P. V., Garrett, T. J., Ferek, R. J., Strader, S. R., Hegg, D. A., Frick, G. M., Hoppel, W. A., Gasparovic, R. F., Russell, L. M., Johnson, D. W., O’Dowd, C., Durkee, P. A., Nielsen, K. E., and Innis, G.: Emissions from Ships with respect to Their Effects on Clouds, J. Atmos. Sci., 57(16), 2656-2670, 2000.

Hoppel, W. A., Fitzgerald, J. W., Frick, G. M., Larson, R. E., and Mack, E. J.: Aerosol size distributions and optical properties found in the marine boundary layer over the Atlantic Ocean, J. Geophys. Res. 95, 3659-3686, 1990.

Huebert, B. J., Wylie, D. J., Zhuang, L., and Heath, J. A.: Production and loss of methanesulfonate and non-sea salt sulfate in the equatorial Pacific marine boundary layer, Geophys. Res. Lett., 23, 737-740, 1996.

Hynes, A. J., Wine, P. H., and Semmes, D. H..: Kinetics and mechanism of $\mathrm{OH}$ reactions with organic sulfides, J. Phys. Chem., 90(17), 4148-4156, 1986.

Jayne, J. T., Leard, D. C., Ahang, X., Davidovits, P., Smith, K. A., Kolb, C. E., and Worsnop, D. R.: Development of an Aerosol Mass Spectrometer for Size and Composition Analysis of Submicron Particles, Aerosol Sci. Tech., 33, 49-70, 2000.

Jimenez, J. L., Jayne, J. T., Shi, Q., Kolb, C. E., Worsnop, D. R., Yourshaw, I., Seinfeld, J. H., Flagan, R. C., Zhang, X., Smith, K. A., Morris, J. W., and Davidovits, P.: Ambient aerosol sampling using the Aerodyne Aerosol Mass Spectrometer, J. Geophys. 
Res., 108(D7), 8245-8258, 2003.

Kulmala, M., Dal Maso, M., Makela, J. M., Pirjola, L., Vakeva, M., Aalto, P., Miikkulainen, P., Hameri, K., and O'Dowd, C.: On the formation, growth and composition of nucleation mode particles, Tellus, 53B, 479-490, 2001.

Law, C. S., Crawford, W. R., Smith, M. J., Boyd, P. W., Wong, C. S., Nojiri, Y., Robert, M., Abraham, E. R., Johnson, W. K., Forsland, V., and Arychuk, M.: Patch evolution and the biogeochemical impact of entrainment during an iron fertilisation experiment in the sub-Arctic Pacific, Deep-Sea Res. Pt. II, 53, 2012-2033, 2006.

Leaitch, W. R., Bottenheim, J. W., Biesenthal, T. A., Li, S.-M., Liu, P. S. K., Asalian, K., Dryfhout-Clark, H., Hopper, F., and Brechtel, F.: A case study of gas-to-particle conversion in an eastern Canadian forest, J. Geophys. Res., 104, 8095-8112, 1999.

Levasseur, M., Scarratt, M. G., Michaud, S., Merzouk, A., Wong, C. S., Arychuk, M., Richardson, W., Wong, E., Marchetti, A., and Kiyosawa, H.: DMSP and DMS dynamics during a mesoscale iron fertilization experiment in the Northeast Pacific, Part I: Temporal and vertical distributions, Deep-Sea Res. Pt. II, 53, 23532369, 2006

Liu, P. S. K., Deng, R., Smith, K. A., Williams, L. R., Jayne, J. T., Canagaratna, M. R., Moore, K., Onasch, T. B., Worsnop, D. R., and Deshler, T.: Transmission Efficiency of an Aerodynamic Focusing Lens System: Comparison of Model Calculations and Laboratory Measurements for the Aerodyne Aerosol Mass Spectrometer, Aerosol Sci. Tech., 41, 721-733, 2007.

Lohmann, U., Broekhuizen, K., Leaitch, R., Shantz, N., and Abbatt, J.: How efficient is cloud droplet formation of organic aerosols?, Geophys. Res. Lett., 31(1-4), L05108, ISSN 00948276, 2004.

Lohmann, U. and Leck, C.: Importance of submicron surface active organic aerosols for pristine Arctic clouds, Tellus, 57B, 261-268, 2005.

Marshall, J., Lohmann, U., Leaitch, W. R., Shantz, N., Phinney, L., Toom-Sauntry, D., and Sharma, S.: Optical Properties of aerosol particles over the north-east Pacific, J. Appl. Meteorol., 44, 1206-1220, 2005.

National Institute of Standards and Technology (NIST) Standard Reference Database 69: NIST Chemistry WebBook, http://webbook.nist.gov/cgi/cbook.cgi?Name=methanesulfonic+ acid\&Units=SI\&cMS=on last access: 16 September 2008 .

Norman, A.-L., Anlauf, K., Hayden, K., Thompson, B., Brook, J. R., Li, S.-M., and Bottenheim, J.: Aerosol sulphate and its oxidation on the Pacific NW coast: $\mathrm{S}$ and $\mathrm{O}$ isotopes in $\mathrm{PM}_{2.5}$, Atmos. Environ., 40(15), 2676-2689, 2006.

Norman, A. L. and Wadleigh, M. A.: Dimethylsulphide (DMS) and its oxidation to sulphur dioxide downwind during SERIES: A model for DMS flux over the Pacific Ocean, in: Air Pollution Modeling and Its Application XVII, edited by: Borrego, C. and Norman, A. L., Kluwer Academic, New York, 237-244, 2007.

O'Dowd, C. D., Facchini, M. C., Cavalli, F., Ceburnis, D., Mircea, M., Decesari, S., Fuzzi, S., Yoon, Y. J., and Putaud, J.-P.: Biogenically driven organic contribution to marine aerosol, Nature, 431, 676-680, 2004.

Peng, Y., Lohmann, U., Leaitch, R., Banic, C., and Couture, M.: The cloud-albedo droplet effective radius relationship for clean and polluted clouds from RACE and FIRE.ACE, J. Geophys. Res., 107, 4106, ISSN 01480227, 2002.
Phinney, L., Leaitch, W. R., Lohmann, U., Boudries, H., Worsnop, D. R., Jayne, J. T., Toom-Sauntry, D., Wadleigh, M., Sharma, S., and Shantz, N.: Characterization of Aerosol Over the Sub-arctic NE Pacific During SERIES, Deep-Sea Res. Pt. II, 53, 2410 2433, 2006.

Pierce, J. R., Chen, K., and Adams, P. J.: Contribution of primary carbonaceous aerosol to cloud condensation nuclei: processes and uncertainties evaluated with a global aerosol microphysics model, Atmos. Chem. Phys., 7, 5447-5466, 2007, http://www.atmos-chem-phys.net/7/5447/2007/.

Pirjola, L., O'Dowd, C. D., Brooks, I. M., and Kulmala, M.: Can new particle formation occur in the clean marine boundary layer?, J. Geophys. Res., 105, 26531-26546, 2000.

Quinn, P. K. and Bates, T.: Regional aerosol properties: Comparisons of boundary layer measurements from ACE 1, ACE 2, Aerosols99, INDOEX, ACE Asia, TARFOX, and NEAQS, J. Geophys. Res., 110, D14202, doi:10.1029/2004JD004755, 2005.

Quinn, P. K., Asher, W. E., and Charleson, R. J.: Equilibria of the Marine Multiphase Ammonia System, J. Atmos. Chem., 14, $11-$ 30, 1992.

Quinn, P. K., Covert, D. S., Bates, T. S., Kaspustin, V. N., RamseyBell, D. C., and McInnes, L. M.: Dimethylsulfide/cloud condensation nuclei/climate system: Relevant size-resolved measurements of the chemical and physical properties of atmospheric aerosol particles, J. Geophys. Res., 98, 10411-10427, 1993.

Russell, L. M., Seinfeld, J. H., Flagan, R. C., Ferek, R. J., Hegg, D. A., Hobbs, P. V., Wobrock, W., Flossman, A., O’Dowd, C. D., Nielsen, K. E., and Durkee, P. A.: Aerosol dynamics in ship tracks, J. Geophys. Res., 104, 31077-31095, 1999.

Russell, L. M., Noone, K. J., Ferek, R. J., Pockalny, R. A., Flagan, R. C., and Seingeld, J. H.: Combustion Organic Aerosol as Cloud Condensation Nuclei in Ship Tracks, J. Atmos. Sci., 57, 25912606, 2000.

Shantz, N. C., Leaitch, W. R., and Caffrey, P. F.: Effects of organics of low solubility on the growth rate of cloud droplets, J. Geophys Res. 108(D5), AAC 5-1-AAC 5-9, doi:10.1029/2002JD002540, 2003.

Shantz, N. C., Leaitch, W. R., Phinney, L., Mozurkewich, M., and Toom-Sauntry, D.: The effect of organic compounds on the growth rate of cloud droplets in marine and forest settings, Atmos. Chem. Phys., 8, 5869-5887, 2008,

http://www.atmos-chem-phys.net/8/5869/2008/.

Shaw, G.: Bio-Controlled Thermostasis Involving the Sulfur Cycle, Climatic Change, 5, 297-303, 1983.

Sievering, H., Cainey, J., Harvey, M., McGregor, J., Nichol, S., and Quinn, P.: Aerosol non-sea-salt sulphate in the remote marine boundary layer under clear-sky and normal cloudiness conditions: Ocean-derived biogenic alkalinity enhances sea-salt sulfate production by ozone oxidation, J. Geophys. Res., 109, D19317, doi:10.1029/2003JD004315, 2004.

Snider, J. R., Petters, M. D., Wechsler, P., and Liu, P. S. K.: Supersaturation in the Wyoming $\mathrm{CCN}$ instrument, J. Atmos. Ocean. Tech., 23, 1323-1339, 2006.

TSI Model 3025A Ultrafine Condensation Particle Counter Instruction Manual, P/N 1933762, available by contacting TSI at www.TSI.com., Revision 1, 2002.

Twomey, S.: Pollution and the Planetary Albedo, Atmos. Environ., 8, 1251-1256, 1974. 
Wadleigh, M. A., Norman, A. L., Burridge, C. C., Scarratt, M., Levasseur, M., Sharma, S., and Wong, C. S.: Trends in atmospheric DMS resulting from the SERIES iron enrichment experiment in the subarctic Pacific Ocean, submitted to Deep-Sea Res. Pt. II., 2002.

Wang, J., Lee, Y.-N., Daum, P. H., Jayne, J., and Alexander, M. L.: Effects of aerosol organics on cloud condensation nucleus $(\mathrm{CCN})$ concentration and first indirect aerosol effect, Atmos. Chem. Phys., 8, 6325-6339, 2008, http://www.atmos-chem-phys.net/8/6325/2008/.

Weber, R.J., McMurry, P.H., Mauldin, L., Tanner, D.J., Eisele, F.L., Brechtel, F.J., Kreidenweis, S. M., Kok, G.L., Schillawski, R.D., and Baumgardner, D.: A study of new particle formation and growth involving biogenic and trace gas species measured during ACE 1, J. Geophys. Res., 103, 16385-16396, 1998.
Wine, P. H., Kreutter, N. M., Gump, C. A., and Ravishankara, A. R.: Kinetics of $\mathrm{OH}$ reactions with the atmospheric sulphur compounds $\mathrm{H}_{2} \mathrm{~S}, \mathrm{CH}_{3} \mathrm{SH}, \mathrm{CH}_{3} \mathrm{SCH}_{3}$, and $\mathrm{CH}_{3} \mathrm{SSCH}_{3}$, J. Phys. Chem., 85(18), 2660-2665, 1981.

Zhang, X., Smith, K. A., Worsnop, D. R., Jimenez, J., Jayne, J. T., and Kolb, C. E.: A Numerical Characterization of Particle Beam Collimation by an Aerodynamic Lens-Nozzle System, Part 1, An Individual Lens or Nozzle, Aerosol Sci. Tech., 36, 617-631, doi:10.108/02786820252883856, 2002.

Zorn, S. R., Drewnick, F., Schott, M., Hoffmann, T., and Borrmann, S.: Characterization of the South Atlantic marine boundary layer aerosol using an aerodyne aerosol mass spectrometer, Atmos. Chem. Phys., 8, 4711-4728, 2008, http://www.atmos-chem-phys.net/8/4711/2008/. 